Centro de Estudios Constitucionales de Chile Universidad de Talca

"Problemática Constitucional del estado de emergencia en Perú: Algunas cuestiones fundamentales"

Abraham Siles

\title{
PROBLEMÁTICA CONSTITUCIONAL DEL ESTADO DE EMERGENCIA EN PERÚ: ALGUNAS CUESTIONES FUNDAMENTALES
}

\section{Constitutional problems of the state of emergency in Perú: Some ESSENTIAL ISSUES}

\author{
Abraham Siles* \\ Pontificia Universidad Católica del Perú \\ asiles@pucp.pe
}

\begin{abstract}
RESUMEN: El artículo muestra que el empleo del estado de emergencia se halla "normalizado" en Perú. Analiza las deficiencias de la legislación sobre la materia, en particular su carácter fragmentario, incompleto y carente de sistematicidad, como también la insuficiencia de la jurisprudencia constitucional. Propone un cambio en la Constitución que regule tres modalidades de régimen de excepción, en vez de dos, de suerte de incorporar como modalidad autónoma el estado de alarma observable en otros ordenamientos constitucionales. Plantea introducir controles más eficaces sobre el modelo de autoinvestidura para la proclamación del estado de emergencia y la asunción de los poderes excepcionales por el Ejecutivo. Defiende una lectura de las causales de emergencia constitucional, a la luz del Derecho Internacional de los Derechos Humanos, de manera de exigir siempre que exista una situación de afectación de la vida nacional (una "amenaza existencial"). Y procura un cumplimiento estricto del principio de temporalidad, mediante una adaptación del principio de "escala creciente de mayorias" sostenido por Bruce Ackerman.

ABSTRACT: The article shows that the use of the state of emergency is "normalized" in Peru. It analyzes the deficiencies of the applicable legislation and, in particular, its fragmentary, incomplete and lack of sistemacity character, as well as the insufficiency of constitutional precedents. It proposes an amendment of the Constitution to regulate three types of regime of exception, instead of two, to include the state of alarm as an independent regime as it exists in other constitutional governments. It suggests to include more effective controls on the auto-investiture model for the declaration of the state of emergency and the assumption of exceptional faculties by the executive. It defends an analysis of the grounds for the emergency in light of the International Human Rights Law to demand the existence of a situation that affects the national life (an "existential threat"). And it intends a strict compliance with the principle of temporality through an adaptation of the principle of "supermajoritarian escalator" as stated by Bruce Ackerman.
\end{abstract}

\footnotetext{
* Profesor de Derecho Constitucional de la Pontificia Universidad Católica del Perú, coordinador del Grupo de Investigación en Derecho Constitucional y Derechos Fundamentales (GIDCYDEF), editor general de la revista Derecho PUCP.
} 
PALABRAS CLAVE: Estado de emergencia, régimen de excepción, Constitución de emergencia, poderes de emergencia, amenaza existencial.

KEY words: State of emergency, regime of exception, constitutional anormality, emergency constitution, emergency powers, existential threat

\section{INTRODUCCIÓN}

El presente artículo aborda algunas de las cuestiones más relevantes que plantea la disciplina jurídico-constitucional del estado de emergencia en Perú. Conviene explicitar que la idea que subyace a esta investigación es la de determinar si es posible, y qué se requiere para ello, que el modelo de Estado constitucional y democrático de Derecho sujete a límites la situación extrema que representa el estado de emergencia -y, en general, el régimen de excepción- frente a las crisis constitucionales de naturaleza político-social (guerras, subversión, terrorismo, revueltas populares) ${ }^{1}$.

El artículo intenta mostrar que la normativa sobre la materia es deficiente, tanto a nivel constitucional como legal, debido a diversas causas: errores de diseño o estructuración institucional, legislación fragmentaria e incompleta, inclusión subordinada de normas legales sobre regímenes de excepción en leyes sobre uso de la fuerza por militares, indeterminaciones y omisiones normativas, elecciones interpretativas controversiales, y debilidad de controles sobre los poderes concentrados en el Ejecutivo, entre otras.

Asimismo, el artículo procura exponer que la práctica constitucional peruana ha sido también deficiente en este ámbito de la vida institucional del país, pues ha permitido el quebrantamiento de la Constitución y la comisión de violaciones graves y sistemáticas de los derechos fundamentales en el marco de la guerra interna que padeció la patria (1980-2000), mientras, en el período posterior a ésta, se mantienen errores al enfrentar la alianza entre remanentes de Sendero Luminoso (grupo subversivo y terrorista) y bandas de narcotraficantes que operan en el Valle de los Ríos Apurímac, Ene y Mantaro (VRAEM), así como se observan deficiencias en la, más reciente, aplicación de la Constitución de emergencia al combate de

\footnotetext{
1 Agradezco a César Landa, Elena Alvites, David Lovatón, Abraham García y Marco Rodríguez, miembros del Grupo de Investigación en Derecho Constitucional y Derechos Fundamentales (GIDCYDEF), por la reunión sostenida para discutir una versión preliminar de este artículo y por sus valiosos comentarios y sugerencias para mejorarlo. He tratado de recoger la mayoría de sus recomendaciones, aunque me excuso por no haberlas seguido en todos los casos. La responsabilidad por el resultado es, desde luego, enteramente mía.
} 
la delincuencia común para el mantenimiento de la seguridad ciudadana (y aun, en ocasiones, a la represión de la protesta social).

El trabajo igualmente explora cómo la jurisprudencia del Tribunal Constitucional peruano, ciertamente escasa y tardía, contribuye poco (por debajo de lo necesario) a superar esta situación, ya que, si bien ha enunciado principios y ha formulado un marco general sobre el estado de emergencia -y sobre el régimen de excepción en su conjunto-, así como se ha pronunciado sobre distintos aspectos específicos, una serie de cuestiones cruciales no han sido precisadas o corregidas, incurriendo a veces el Tribunal Constitucional en interpretaciones y decisiones discutibles, o, en otras ocasiones, omitiendo pronunciarse sobre determinados puntos que requieren definición (por ejemplo, sobre las prórrogas sucesivas del estado de emergencia).

Si bien el Derecho Internacional de los Derechos Humanos regula de manera integral los estados de excepción, y en tal medida complementa y refuerza el precario marco normativo y las débiles prácticas institucionales a nivel nacional, en este artículo se acude a él de manera especial para el examen de la cuestión de las causales que justifican la declaración del estado de emergencia constitucional, en relación con la exigencia de afectar la vida de la nación, donde el ordenamiento internacional de los derechos humanos tiene particular relevancia.

Por limitaciones de espacio (y por su propia naturaleza) el artículo no puede abordar todos los aspectos de la problemática, por lo que se concentra en determinadas cuestiones generales y de diseño institucional, así como en algunas cuestiones específicas poco estudiadas o que requieren ser debatidas y desarrolladas con mayor precisión (a veces también requieren la introducción de enmiendas o ajustes). Se ha privilegiado, así, junto a la presencia de la institución a lo largo de la historia, estudiar la fragmentación de la normativa, el dilema entre modelo dual o tripartito de régimen de excepción y los principios orientadores, la proclamación de la emergencia y la autoinvestidura de quien ejerce los poderes extraordinarios, la definición del contenido y gravedad de las causales (en especial, por lo que atañe a la exigencia de afectar la vida de la nación), y la cuestión del principio de temporalidad y las prórrogas sucesivas.

Quedan fuera del objeto de estudio, pese a su indudable importancia, los efectos del estado de emergencia sobre los derechos fundamentales, el rol de las Fuerzas Armadas respecto del control del orden interno, y los pormenores del control jurisdiccional y político sobre la proclamación de la emergencia y las medidas adoptadas a su amparo, que deberán ser materia de próximos trabajos de investigación académica que den continuidad a este esfuerzo inicial. 


\section{LA EMERGENCIA CONSTITUCIONAL COMO CONSTANTE HISTÓRICA}

En Perú, el estado de emergencia-o, en términos más generales, el régimen de excepción- se erige como uno de los principales desafíos al Estado constitucional y democrático de Derecho. Diversas causas convergen para ello. No sólo se trata de la naturaleza paradójica de la institución, la cual, en buena cuenta, consiste en suspender cláusulas primordiales de la Constitución con la finalidad de salvarla ${ }^{2}$. Tampoco es solamente que existan deficiencias en la normativa en vigor o en la jurisprudencia del Tribunal Constitucional, como se tendrá ocasión de apreciar en este trabajo. Quizá, sobre todo, la cuestión reside en la presencia histórica del estado de emergencia en la vida constitucional peruana. $\mathrm{O}$, dicho con mayor precisión, en la configuración concreta del estado de emergencia en la historia constitucional del país, esto es, en las formas (distorsionadas y excesivas) en las que ha sido aplicado y en sus efectos (ciertamente nocivos, tal vez devastadores), tanto inmediatos como de largo aliento, sobre el tejido social e institucional del Perú.

Y es que, desde que la Carta de 1979 recogiera la figura por primera vez en un texto constitucional peruano ${ }^{3}$, el estado de emergencia ha sido aplicado innumerables veces, en multiplicidad de situaciones, pasando así a formar parte del panorama institucional ordinario del país. En la década de los ochenta del siglo pasado, ante la brutal arremetida de la violencia política de Sendero Luminoso (más tarde, también del Movimiento Revolucionario Túpac Amaru, MRTA), el Estado optó por una respuesta fundamentalmente militar y represiva, apoyada en la declaración del estado de emergencia, que trajo como consecuencia violaciones masivas y sistemáticas de los derechos humanos ${ }^{4}$, pese a que la Carta entonces vigente, lo mismo que la actual, sólo permitía la suspensión o restricción del ejercicio de cuatro derechos fundamentales (libertad y seguridad personales, inviolabilidad del domicilio, libertad de reunión y libertad de tránsito en el territorio nacional). Desde mediados de dicha década, varios estudiosos del régimen constitucional

2 Véanse Levinson y Balkin (2010), p. 1795; Benazzo (2004), p. 3. Véase también Siles (2015), p. 75.

3 Véanse García-Sayán (1987), pp. 107-108; Palacios (1988), pp. 66 y 72-73.

4 Véanse Rubio (1989), pp. 235-250 y 259; Eguiguren (1989), pp. 270-271. 
de excepción constataron su duración prolongada ${ }^{5}$, fenómeno que la doctrina conoce como la "normalización de la emergencia" 6 .

Las cosas no fueron diferentes en el siguiente decenio, ni siquiera con los cambios en la materia introducidos por la Constitución de 1993 (algunos, ciertamente notables, como la consagración del contralor jurisdiccional parcial bajo régimen de excepción), y pese a la captura de los principales líderes de los grupos subversivos y al consiguiente desbaratamiento de éstos. A lo largo de los años noventa, durante la Presidencia de la República de Alberto Fujimori, el país mantuvo el régimen de excepción constitucional en diversas partes del suelo patrio, siempre como medida para hacer frente a la subversión?

Ya en el siglo XXI, si bien las actividades subversivas se han visto considerablemente reducidas, no han desaparecido, por lo que el Ejecutivo ha seguido aplicando el estado de emergencia en aquellas zonas donde continúan operando los remanentes de Sendero Luminoso (en la actualidad, en el VRAEM; hasta hace poco, también en el Alto Huallaga $)^{8}$.

A ello debe añadirse, sin embargo, el creciente uso del estado de emergencia frente a los desastres naturales ${ }^{9}$, quizá más preocupante aún, como medio para garantizar la seguridad ciudadana y combatir ciertas formas de delincuencia común (lo que ocurre ahora en la Provincia Constitucional del Callao y en las provincias del Santa y Casma, en el departamento de Áncash ${ }^{10}$ ). Igual mención merece el empleo de las Fuerzas Armadas para colaborar en tareas de control del orden interno ante acciones de protesta social, sin proclamación del régimen de excepción ${ }^{11}$, práctica que plantea serias dudas de constitucionalidad pese a haber sido convalidada por la jurisprudencia del Tribunal Constitucional (como se expone en el siguiente acápite).

\footnotetext{
5 Véanse Coloma (1985), pp. i-ii, 80-81, 98-105 y 109-110; Palacios (1988), pp. 83-84 y 156; Power (1990), pp. 17, 172 (nota 42), 173, 233-239 y 274; VARGaS (1995), pp. 208 y 210. Véase también KeItH y POE (2004), pp. 1078 y 1097.

6 Véanse Ackerman (2007), p. 70; Gross y Ní Aoláin (2006), pp. 228 y ss.; Vergottini (2004), p. 23; Benazzo (2004), p. 4; Dyzenhaus (2002), pp. 28-29.

7 Véase SiLEs (2015), pp. 79-82.

8 Véase SCHeinin (2010), párr. 31. Véase también Siles (2015), pp. 82-83.

9 Véase Grández (2012), pp. 205-211.

10 Véanse decreto supremo No 036-2017-PCM (2017); decreto supremo No 019-2017-PCM (2017).

11 Véanse Pérez (2012), pp. 17-25; IDL (2012); Soberón y Jugo (2010), pp. 58-67.
} 
No debe perderse de vista, en todo caso, que este reiterado uso (abusivo) del estado de emergencia bajo las Constituciones de 1979 y 1993 se inscribe en un proceso histórico aún mayor, que abarca todo el período republicano. En efecto, desde la misma fundación de la República y del orden constitucional y democrático, se ha forjado en Perú una tradición constitucional que echa mano de los estados de excepción para enfrentar crisis políticas y sociales ${ }^{12}$, además de las provocadas por las catástrofes naturales.

En época reciente, el fenómeno más extremo de aplicación del régimen de excepción viene dado por lo ocurrido en las dos últimas décadas del siglo XX, con ocasión de la guerra interna que el país vivió ante el desafío subversivo y terrorista de Sendero Luminoso y el Movimiento Revolucionario Túpac Amaru (MRTA), y la respuesta represiva del Estado a través de las Fuerzas Armadas y Policiales. Es de sobra conocida la magnitud de esta tragedia bélica, de hondo impacto en el devenir del país, para la cual la proclamación de estados de emergencia y la participación de las Fuerzas Armadas constituyeron elementos cruciales, al favorecer el abuso de los poderes extraordinarios, la "abdicación de la autoridad democrática" y una delegación irrestricta en las Fuerzas Armadas de la conducción de la "guerra contra el terrorismo"13.

El horror de la guerra interna y el mal uso del estado de emergencia llevaron, precisamente, a la Comisión de la Verdad y Reconciliación (CVR) a formular ciertas recomendaciones relativas a la regulación y empleo del régimen de excepción constitucional. En efecto, la CVR sugirió una "transformación sustancial" del marco jurídico regulatorio de la participación de las Fuerzas Armadas y Policiales en los períodos de anormalidad constitucional, así como, en particular, "la adopción de una ley sobre regímenes de excepción, que articule los objetivos de eficacia en las labores de control del orden interno y el respeto de los derechos humanos, dentro de los estrictos marcos del Estado de Derecho"14.

12 Véase Siles (2015), pp. 79-82. Véanse también Aljovín (2000), pp. 261 y ss.; Rey de Castro (2010), pp. 165 y ss.

13 Véanse CVR (2003), pp. 494 y ss., t-VI; CVR (2003), pp. 364-366, t-VIII; Lerner (2011), p. 60.

14 Véase CVR (2003), p. 522, t-VI. Véase también CVR (2003), pp. 130 y 132, t-IX. 


\section{EL RÉGIMEN JURÍDICO DEL ESTADO DE}

\section{EMERGENCIA: LEGISLACIÓN DISPERSA, FRAGMENTARIA E INCOMPLETA}

Un primer problema, de orden general, que muestra la disciplina jurídica del estado de emergencia en Perú es la ausencia de una regulación integral mediante una ley especial sobre los regímenes de excepción previstos constitucionalmente (artículo 137, Const.). Pese al tiempo transcurrido, el país carece hasta hoy de la ley cuya dramática necesidad advirtiera la CVR.

Desde luego, para la elaboración de esta ley no hace falta que exista mandato expreso en la Constitución. Como se sabe, las Cartas de 1979 y 1993 han excluido la referencia explícita a una ley de desarrollo en esta materia, por contraste con lo estatuido por la Constitución de 1933, cuyo artículo 70, párrafo tercero, estipuló que "[1]a ley determinará las facultades del Poder Ejecutivo durante la suspensión de garantías”. Esta disposición nunca fue cumplida ${ }^{15}$, de manera semejante a lo sucedido con el mandato homólogo del célebre artículo 48 de la Constitución de Weimar ${ }^{16}$. Pero es claro que la ausencia de previsión constitucional expresa no significa que el legislador democrático esté impedido de ejercer sus potestades legislativas en este ámbito. Por el contrario, llama ciertamente la atención su abstención en un período de tiempo tan amplio (más de siete lustros, si contamos desde que la Carta de 1979 adquirió plena vigencia, en julio de 1980).

La falta de una ley integral sobre los regímenes de excepción impide que el país cuente, en tema de tanta importancia, con una regulación completa, más precisa, clara y sistemática. Ello perjudica la correcta comprensión de las instituciones de excepción constitucional y, aún más relevante, su adecuado uso y aplicación práctica por las autoridades estatales ${ }^{17}$. En la actualidad, lo que existe en el Perú son leyes y disposiciones legales dispersas, fragmentarias e incompletas, contenidas en distintos cuerpos normativos que abordan aspectos específicos o parciales de la materia. Es decir, justamente, lo contrario de lo que se requiere. El siguiente cuadro sintetiza la situación y permite apreciar, asimismo, la evolución normativa en términos generales. Incluye tanto la legislación como la jurisprudencia relevante del Tribunal Constitucional.

15 Véanse Rubio y Bernales (1983), p. 217; Eguiguren (1989), p. 266; Palacios (1988), p. 64.

16 Véanse Rossiter (2011), p. 32; Bühler (2010), p. 207; Baño (2013), p. XLIII.

17 Otros países cuentan con leyes que regulan comprehensivamente los estados de excepción. Véanse, por ejemplo: España (Ley Orgánica 4/1981 (1981)); Colombia (ley No 137 (1994)); Canadá (Emergencies Act, R.S.C. (1985)); Venezuela (Ley Orgánica sobre Estados de Excepción (2001)). 


\section{Leyes y sentencias del Tribunal Constitucional sobre Fuerzas Armadas, estados de excepción y uso de la fuerza}

\begin{tabular}{|c|c|c|}
\hline $\begin{array}{l}\text { Fuerzas Armadas con estado } \\
\text { de excepción }\end{array}$ & $\begin{array}{c}\text { Fuerzas Armadas sin estado } \\
\text { de excepción }\end{array}$ & $\begin{array}{l}\text { Fuerzas Armadas y uso de la } \\
\text { fuerza }\end{array}$ \\
\hline $\begin{array}{l}\text { Ley No } 24150 \text { (EP, } 7 \text { de } \\
\text { junio de } 1985) \\
\text { Regula el control del orden } \\
\text { interno por las FF.AA. duran- } \\
\text { te los estados de excepción. }\end{array}$ & $\begin{array}{l}\text { Decreto Legislativo } 738 \\
(E P, 12 \text { de noviembre de } \\
1991)\end{array}$ & $\begin{array}{l}\text { Ley No } 29166 \text { (EP, } 20 \text { de } \\
\text { diciembre de 2007). }\end{array}$ \\
\hline $\begin{array}{l}\text { Decreto Legislativo } 749 \text { (EP, } \\
12 \text { de noviembre de } 1991 \text { ) } \\
\text { Modifica el art. } 5 \text { de la Ley } \\
24150 .\end{array}$ & $\begin{array}{l}\text { Ley No } 25410 \text { (EP, } 12 \text { de } \\
\text { marzo de 1992) } \\
\text { Sustituye el art. } 2 \text { del De- } \\
\text { creto Legislativo } 738 .\end{array}$ & $\begin{array}{l}\text { STC 00002-2008-AI (web TC, } \\
14 \text { de septiembre de 2009) } \\
\text { Examina la constitucionalidad } \\
\text { de la Ley } 29166 .\end{array}$ \\
\hline $\begin{array}{l}\text { Ley No } 25397 \text { (EP, } 9 \text { de } \\
\text { febrero de 1992) } \\
\text { Regula el control parlamen- } \\
\text { tario sobre los actos norma- } \\
\text { tivos del Presidente de la } \\
\text { República. }\end{array}$ & $\begin{array}{l}\text { Ley No } 28222 \text { (EP, } 18 \text { de } \\
\text { mayo de 2004) } \\
\text { Modifica el artículo único } \\
\text { de la Ley } 25410 .\end{array}$ & $\begin{array}{l}\text { Resolución aclaratoria del TC } \\
\text { (Exp. 00002-2008-AI (web } \\
\text { TC, } 18 \text { de septiembre de } \\
\text { 2009). }\end{array}$ \\
\hline $\begin{array}{l}\text { STC 017-2003-AI/TC (web } \\
\text { TC, } 23 \text { de agosto de } 2004 \text { ) } \\
\text { Examina la constitucionali- } \\
\text { dad de la Ley } 24150 .\end{array}$ & & $\begin{array}{l}\text { Decreto Legislativo } 1095 \text { (EP, } \\
1 \text { de septiembre de 2010). }\end{array}$ \\
\hline $\begin{array}{l}\text { Resolución aclaratoria del } \\
\text { TC (Exp. 017-2003-AI/TC) } \\
\text { (web TC, } 28 \text { de septiembre } \\
\text { de 2004). }\end{array}$ & & $\begin{array}{l}\text { STC 00022-2011-PI/TC (web } \\
\text { TC, } 18 \text { agosto 2015) } \\
\text { Examina la constitucionalidad } \\
\text { del Decreto Legislativo } 1095 .\end{array}$ \\
\hline
\end{tabular}

Fuentes: El Peruano y página web del Tribunal Constitucional.

Elaboración propia.

Como se puede observar, desde mediados de los años ochenta del siglo pasado hasta la actualidad, el legislador se ha ocupado de establecer normas relativas al rol de las Fuerzas Armadas durante los estados excepcionales. Esta ha sido su preocupación principal, acaso debido a la tradicional influencia de la corporación militar en el sistema político peruano ${ }^{18}$. Se trata, pues, de una regulación parcial e incompleta, en la medida en que no aborda todos los elementos de la anormalidad constitucional. Por el contrario, deja de lado algunos aspectos de especial

18 Véanse Rubio (1989), pp. 231-235; DonaYre (2009), pp. 175-176, t-II. Véanse también Rospigliosi (2001), pp. 170 y ss.; SÁNCHEZ (2011), p. 20. 
trascendencia, tales como la definición de los hechos habilitantes, la incidencia sobre los derechos fundamentales, los casos de intervención de las Fuerzas Armadas, y los mecanismos de control jurisdiccional y político.

Como quiera que fuere, la ley No 24.150, que fue puesta en vigor en junio de 1985, con retraso respecto del ingreso de las Fuerzas Armadas a enfrentar la subversión senderista en Ayacucho y zonas aledañas (ingreso producido en diciembre de $1982^{19}$ ), fue objeto de críticas por su inconsistencia interna. Y es que algunas de sus disposiciones restringían diversos poderes de los Comandos Político-Militares a tareas de mera coordinación o proposición (artículo 5), mientras otras cláusulas presuponían un ejercicio amplio de potestades de gobierno en reemplazo de las autoridades civiles (artículos 2 y 11) ${ }^{20}$.

El descontento de sectores importantes de la sociedad civil y de las propias Fuerzas Armadas llevó a una reforma legal en noviembre de 1991. El Decreto Legislativo No 749 modificó el artículo 5 de la ley, y se decantó por fortalecer los poderes militares bajo régimen de excepción, lo que también fue objeto de críticas severas $^{21}$. Casi trece años más tarde, empero, el Tribunal Constitucional declararía la inconstitucionalidad de las más importantes de estas regulaciones y estipularía la interpretación admisible de otras cláusulas para hacerlas conformes a la Carta Fundamental ${ }^{22}$.

Ahora bien, parece harto significativo que, junto con leyes atinentes al rol de las Fuerzas Armadas durante los estados de excepción, haya sido aprobada legislación que asigna a la milicia atribuciones para intervenir en tareas de control del orden interno sin declaración de un estado de emergencia o de sitio (como una suerte de extensión, cuya constitucionalidad debe ser discutida, de las modalidades excepcionales contempladas en los textos constitucionales vigentes en cada caso). Ello ocurre desde el año 1991 (Decreto Legislativo No 738) y es confirmado con modificaciones parciales en 1992 y 2004 (ley No 25.410 y ley No 28.222, respectivamente). El Tribunal Constitucional, por lo demás, ha convalidado este rol de las Fuerzas Armadas en dos pronunciamientos de especial significación,

\footnotetext{
19 Véanse CVR (2004), pp. 104-105, t-I.

20 Véase Rubio (1989), pp. 248-249. Véase también Comisión Especial del Senado sobre las Causas de la Violencia y Alternativas de Pacificación en el Perú (1989), pp. 295 y 304-308.

21 Véase CVR (2003), pp. 212-216, t-III.

22 Véase Sentencia del Tribunal Constitucional No 017-2003-AI-TC, de 16 de marzo de 2004.
} 
en base a una interpretación de dudosa constitucionalidad que debe ser objeto de análisis por la investigación académica ${ }^{23}$.

Por ende, cabe destacar asimismo que, desde agosto del año 2004, cuando emite la sentencia que examina la constitucionalidad de la ley No 24.150, hasta fecha reciente (agosto de 2015), cuando revisa la compatibilidad constitucional del Decreto Legislativo No 1095, el Tribunal Constitucional aparece como un actor relevante en la configuración del marco normativo sobre regímenes de excepción en Perú.

También debe ser resaltado, en un arco temporal que excede las tres décadas, el hecho que la orientación legislativa haya experimentado una inflexión. En efecto, durante los primeros veinte años (desde 1985 hasta 2004), la legislación fue elaborada para establecer las potestades y los deberes de las Fuerzas Armadas, en especial respecto del control del orden interno, bajo régimen de excepción (a lo que se agregó, desde 1991, como ha sido indicado, la potestad de hacerlo también sin estado excepcional formalmente proclamado).

Sin embargo, desde el año 2007, cuando entra en vigor la ley No 29.166, la legislación cambia el eje de la regulación, el cual pasa a ser la temática del empleo de la fuerza por los miembros de la corporación militar. Tanto la ley No 29.166 como el Decreto Legislativo No 1095, vigente en la actualidad, incluyen normas sobre régimen de excepción en el marco de la regulación sobre uso de la fuerza por las Fuerzas Armadas, subordinando dichas normas al objeto principal de la regulación.

A esta legislación, que se ocupa de los regímenes de excepción en función de las Fuerzas Armadas, debe añadirse ahora las disposiciones sobre protección de derechos fundamentales bajo estados de excepción contenidas en el Código Procesal Constitucional, especialmente el artículo 23, que desarrolla los controles jurisdiccionales de constitucionalidad basados en los principios de razonabilidad

23 Véanse Sentencia del Tribunal Constitucional No 00002-2008-AI, de 9 de septiembre de 2009, cs. 32-52 y puntos resolutorios 3 y 7 (véanse también los respectivos votos singulares de los magistrados Mesía Ramírez y Calle Hayen); Sentencia del Tribunal Constitucional No 00022-2011-PI/TC, de 8 de julio de 2015, cs. 384-398 y puntos resolutorios 1.1 y 1.2 (véanse también los respectivos votos singulares de los magistrados Espinosa-Saldaña, Miranda Canales y Blume Fortini, así como el de la magistrada Ledesma Narváez). Espero ocuparme de esta cuestión en un nuevo artículo sobre el estado de emergencia en Perú que aborde varios temas dejados de lado en esta oportunidad, entre ellos, el relativo al rol de las Fuerzas Armadas en el control del orden interno sin proclamación de la excepcionalidad constitucional. 
y proporcionalidad, en armonía con los dos párrafos finales del artículo 200 de la Constitución de $1993^{24}$.

Pero tan importantes como las reglas legales, dispersas y fragmentarias, existentes en materia de estados de excepción son las omisiones en que incurren determinados cuerpos normativos que debieran contener estipulaciones vinculadas a esta temática. En particular, es notoria la ausencia de previsiones acerca del control político parlamentario sobre el estado de emergencia (y el de sitio) en el Reglamento del Congreso. Ha de tenerse en cuenta, al respecto, que el Reglamento del Congreso sí contiene normas que regulan en detalle el control político que debe ejercer el Parlamento sobre la legislación delegada, los decretos de urgencia y los tratados ejecutivos (artículos 90 a 92), lo que hace más llamativa la omisión que aquí se refiere.

Por su parte, la Ley No 29.158, Ley Orgánica del Poder Ejecutivo (LOPE) (El Peruano, 20 de diciembre de 2007), no regula con precisión, y ni siquiera en términos generales, las potestades del Ejecutivo en el ámbito de los estados de excepción. Sólo contiene una escueta remisión en el párrafo final de su artículo 11, que estatuye: "Los decretos legislativos, los decretos de urgencia y los decretos supremos sobre estados de excepción están sujetos al control político del Congreso de la República, conforme al procedimiento establecido en su Reglamento". Como se acaba de anotar, el Reglamento del Congreso omite flagrantemente normar el punto relativo a los poderes excepcionales que asume el Ejecutivo en aplicación del artículo 137, Const.

Un análisis jurídico constitucional, no sólo de orden formal sino también sustantivo -el control es esencial en el Estado constitucional y democrático de Derecho-, lleva a concluir que, dada la abstención del Reglamento del Congreso, la ley No 25397, que regula el control parlamentario sobre los actos normativos del Presidente de la República desde febrero de 1992, sigue parcialmente en vigor (aun cuando no haya sido ni sea aplicada), ya que no ha recaído sobre ella derogación expresa ni existe un cuerpo normativo que regule enteramente la materia especial de la que se ocupa ${ }^{25}$.

Queda claro que el enfoque correcto de una eventual regulación integral sobre el estado de emergencia en Perú, y en general sobre los estados de excepción,

24 Véanse Abad (2004), pp. 125-128; Castillo (2005), pp. 12-19.

25 Véanse Delgado-Guembes (2012), pp. 551-553; Defensoría del Pueblo (2003), pp. 104-109; EspinosaSAldaña (2003), pp. 177-178. 
debe colocar en el centro de la preocupación del legislador democrático a la tutela más completa posible sobre la persona humana, su dignidad y los derechos fundamentales que la aseguran, subordinando los demás contenidos y fines del régimen legal a este propósito principal.

\section{El RÉGIMEN DE EXCEPCIÓN EN PeRÚ: MODALIDADES y PRINCIPIOS}

\section{IV.1. El diseño institucional del régimen de excepción: ¿dos o tres modalidades?}

Las Constituciones de los diversos países difieren mucho en el modo de regular los estados de excepción. Hay casos, ciertamente extremos, como el de Bélgica e Italia, cuyas Constituciones no contienen cláusulas sobre la materia ${ }^{26}$, en el entendido de que en ninguna hipótesis debe admitirse la suspensión de la Carta Fundamental, y menos aún la afectación de los derechos constitucionales, ni siquiera ante peligros que amenacen la continuidad de la vida institucional del país ${ }^{27}$.

Otras Constituciones regulan sólo la posibilidad de suspender la protección jurisdiccional de los derechos fundamentales en situaciones de crisis extraordinaria. Ocurre así en Estados Unidos de América, cuyo texto constitucional (de 1787, revisado en 1992) estipula, escuetamente, que "[e]l privilegio del mandato de hábeas corpus no será suspendido, salvo cuando en casos de rebelión o invasión la seguridad pública lo requiera” (artículo I, sección novena, párrafo 2) ${ }^{28}$.

Los ordenamientos constitucionales que sí prevén estados de excepción en la Norma Suprema fluctúan entre consagrar un régimen simple o disciplinar la materia con varios tipos o modalidades de anormalidad constitucional. Ejemplo de la primera opción es el Derecho argentino, cuya Constitución (de 1853, revisada en 1994) recoge la clásica institución del "estado de sitio", estatuyendo que "[e]n caso de conmoción interior o de ataque exterior que pongan en peligro el ejercicio de esta Constitución y de las autoridades creadas por ella, se declarará

\footnotetext{
26 Véanse Benazzo (2004), pp. 12, 13 (nota 15) y 10 (nota 10); Vergottini (2004), p. 24; Tenorio (2010), pp. 154-157.

27 En el temprano debate teórico constitucional, durante las primeras décadas del Estado constitucional y democrático de Derecho, fue Constant (2006), pp. 243 y ss., quien se opuso a la posibilidad de suspender la Constitución con la finalidad proclamada de salvarla, precisamente por las posibilidades de abuso que de allí se derivan.

28 Traducción mía.
} 
en estado de sitio la provincia o territorio en donde exista la perturbación del orden, quedando suspensas allí las garantías constitucionales...” (artículo 23).

Ejemplos de la segunda opción son los ordenamientos jurídicos de España, Colombia y Venezuela, cuyas Cartas Fundamentales recogen diversas modalidades o figuras de excepción, apuntando así a un régimen legal de mayor complejidad. En el caso de España, la Constitución (de 1978, revisada en 2011) prevé los estados de alarma, de excepción y de sitio (artículo 116), mientras que en el caso de Colombia las instituciones son el estado de guerra exterior, el estado de conmoción interior y el estado de emergencia (artículos 212-215 de la Constitución de 1991, revisada en 2013). Finalmente, en el caso de Venezuela, los tipos o modalidades son el estado de alarma, el estado de emergencia económica y el estado de conmoción interior o exterior (artículos 337-339 de la Constitución de 1999, revisada en 2009).

El régimen de excepción peruano representa una situación intermedia. En efecto, el constituyente nacional de 1993 mantuvo el diseño institucional de su inmediato predecesor de 1979, esto es, una regulación compleja pero sólo con dos modalidades: el estado de emergencia y el estado de sitio. Hay que reconocer en esta innovación constitucional un avance respecto de la Carta de 1933, cuyo artículo 70 regulaba de manera simple la institución de la así denominada "suspensión de garantías”, la cual se resentía además de la vaguedad de sus cláusulas, lo que favorecía el ejercicio arbitrario de los poderes extraordinarios del Poder Ejecutivo $^{29}$.

El régimen de excepción dual de las Constituciones peruanas de 1979 y 1993 muestra, sin embargo, un serio inconveniente al regular bajo la modalidad de "estado de emergencia” lo que en rigor son dos situaciones diferentes, que ameritaban ser recogidas en figuras también distintas. $Y$ es que una cosa son las emergencias provocadas por las "catástrofes", en particular las desencadenadas por la furia de la naturaleza, y otra cosa son los desafíos existenciales derivados de acciones de índole socio-política, en especial las que conllevan manifestaciones de violencia organizada grave (tales como subversión, terrorismo o guerra).

Es claro que la diferencia entre estos supuestos no es sólo de grado o cantidad. Se trata, realmente, de fenómenos de distinta naturaleza, por lo que la divergencia cualitativa justificaba (justifica) un tratamiento constitucional diferenciado. Es lo que sucede, por lo demás, en otros ordenamientos. Tanto España como Venezuela

29 Véanse García-Sayán (1988), pp. 105-107; Rubio y Bernales (1983), p. 217; Eguiguren (1989), p. 265; Palacios (1988), pp. 63 y ss. 
reservan el "estado de alarma" para que la autoridad estatal pueda enfrentar las crisis causadas por los desastres naturales y otras emergencias carentes en principio de elementos políticos (por ejemplo, crisis sanitarias y desabastecimiento de productos de primera necesidad), mientras que Colombia prevé en tales hipótesis el "estado de emergencia".

El asunto no es irrelevante ni de menor importancia, ya que parece claro que fenómenos cualitativamente distintos deben estar sujetos a regulaciones apropiadas a cada tipo de circunstancias. Desde luego, ello debiera verse reflejado, por ejemplo, en los requisitos para la proclamación del estado excepcional -mayores o menores según el caso-, así como en el eventual impacto sobre los derechos fundamentales o en la también eventual participación de las Fuerzas Armadas, o en el plazo de duración, su prórroga y otros aspectos de la regulación.

No extraña, por ello, que Eguiguren Praeli haya sostenido que la concepción y los alcances del régimen de excepción de la Carta de 1979 resultaban obsoletos, al constreñirlo mediante una "lógica represiva" orientada de modo exclusivo al mantenimiento o restablecimiento del orden público ante las crisis ${ }^{30}$. Para este autor, en efecto, las emergencias "ajenas al campo estrictamente político y social", tales como las provocadas por desastres naturales (terremotos, inundaciones, sequías) y otros eventos (epidemias, carestía de alimentos y crisis económicas) no pueden ser adecuadamente enfrentadas con atribuciones excepcionales fundamentalmente represivas (poderes para realizar detenciones, allanamientos, disolución de manifestaciones), sino que esta clase de supuestos exige del gobierno "facultades especiales de tipo normativo, administrativo o económico" que no se hallan previstas en el marco constitucional ${ }^{31}$.

Power Manchego-Muñoz también encontró inconveniente el que la Carta de 1979 incluyera bajo la modalidad de estado de emergencia, de un lado, una situación de orden "político-social" (los casos de perturbación de la paz o del orden interno), y, de otro lado, crisis causadas por "hechos naturales" (catástrofes o graves circunstancias que afecten la vida de la Nación) ${ }^{32}$. Si bien no observó, como sí hizo Eguiguren, que los poderes extraordinarios reconocidos por la Constitución servían especialmente frente a las crisis socio-políticas, dada su naturaleza esencialmente represiva (control del orden interno, afectación de derechos fundamentales,

30 Véase Eguiguren (1989), p. 266.

31 Ibíd.

32 Véase POWER (1990), pp. 169-170. 
potestad de ordenar la intervención de las Fuerzas Armadas), Power ManchegoMuñoz tomó como ejemplo el orden constitucional español, que, según ha sido indicado antes, admite tres situaciones excepcionales ${ }^{33}$.

Este autor, en consecuencia, propuso una reforma constitucional dirigida a establecer tres estados de excepción y no solamente dos, atendiendo a sus diferencias cualitativas y, desde luego, con diferentes alcances en atribuciones de la autoridad y efectos derivados: el primero, para catástrofes naturales; el segundo, para casos de perturbación de la paz o del orden interno por actos político-sociales (lo que incluye situaciones de terrorismo o guerrilla); el tercero, para los casos de invasión, guerra exterior, guerra civil o peligro inminente de su producción 34 (supuestos regulados en la Carta de 1979, así como posteriormente en la de 1993, bajo la figura del estado de sitio).

También Eguiguren Praeli consideró necesario introducir una enmienda constitucional para procurar una "reestructuración integral" del régimen de excepción, la cual había de orientarse a superar "el carácter exclusivamente represivo que hoy presenta”, e incidir, en particular, en la incorporación de las emergencias económicas y en otorgar "atribuciones más eficaces al Poder Ejecutivo, a nivel normativo y administrativo" 35 .

\section{IV.2. Constitución de emergencia y principios orientadores}

El estado de excepción constitucional es un régimen especial que se aparta del que está en vigor durante la "normalidad constitucional" y que procura someter una "amenaza existencial", esto es, un peligro de singular gravedad que se cierne sobre la propia vida de la Nación o del Estado ${ }^{36}$. En consecuencia, hace falta otorgar poderes extraordinarios al Ejecutivo y habilitarlo para afectar determinados derechos fundamentales y aun para, eventualmente, recurrir a las Fuerzas Armadas en reemplazo de la Policía, aunque siempre con el objetivo superior de restaurar el funcionamiento normal de las instituciones y preservar la Constitución ${ }^{37}$.

\footnotetext{
33 Ibíd., p. 170.

34 Ibíd., pp. 275-276.

35 Véase Eguiguren (1989), p. 283.

36 Sobre la noción de amenaza existencial, véanse ACKERMAN (2007), pp. 35-36, 39, 82-83, 87, 95; Pérez (2010), p. 9.

37 Véase Siles (2015), p. 74. Véanse también Loewenstein (1979), pp. 284 y ss.; Friedrich (1975) pp. 585-587, t-II.
} 
Lo distintivo de los estados excepcionales es entonces que, una vez declarada formalmente la emergencia por los órganos competentes, el poder queda concentrado en el Gobierno -modificando el cuadro de división de poderes propio de la normalidad constitucional-, Gobierno que recibe potestades extraordinarias con vistas a adoptar medidas prontas y eficaces que permitan al Estado dominar la causa de la crisis ${ }^{38}$. De allí que el Tribunal Constitucional peruano considere que el régimen de excepción se caracteriza por la "concentración del poder, con permisión constitucional, en un solo detentador -normalmente el jefe del Ejecutivo-, mediante la concesión de un conjunto de competencias extraordinarias, a efectos de que la acción estatal sea tan rápida y eficaz como lo exijan las graves circunstancias de anormalidad que afronta la comunidad política" 39 .

Carl Schmitt, en frase impactante que ha hecho fortuna en el ámbito académico, afirmó que soberano es "aquel que decide sobre el estado de excepción", y defendió la tesis de la imposibilidad de someter a límites jurídicos el ejercicio de los poderes extraordinarios para conjurar la emergencia ${ }^{40}$. Giorgio Agamben, a su turno, si bien desde un paradigma teórico sustancialmente distinto, considera que el estado de excepción no es un Derecho especial, a la manera del Derecho de Guerra, sino que, "en cuanto suspensión del propio orden jurídico, define el umbral o el concepto límite" 41 . En fin, sin llegar a adoptar tesis tan extremas, Guillaume Tusseau formula una pregunta fundamental, a saber, si puede la emergencia ser "el momento de la verdad del Derecho Constitucional", esto es, la situación en la cual "el Derecho parece ser revelado", pues, o bien cede ante "el poder o la fuerza bruta", o bien se muestra en aptitud de "enfrentar lo que lo desafía y proveer los medios para hacer frente a lo que lo cuestiona en la más radical de las maneras" 42 .

Serán autores como David Dyzenhaus y Luigi Ferrajoli quienes, tanto en el Derecho anglosajón (Common Law) como en el Derecho de raigambre romanogermánica (Civil Law), defenderán una aproximación a la cuestión de la Cons-

38 Véanse Pérez (2005), p. 1046; Castillo (2005), p. 6; Palacios (1988), p. 47.

39 Véase Sentencia del Tribunal Constitucional No 00002-2008-AI, de 9 de septiembre de 2009, c. 18.

40 Véase Schmitт (1998), pp. 15 y 17. Sobre la frase citada de Schmitt que vincula soberanía y estado excepcional, ha dicho McCormick (1999), p. 121, que "es quizá la más famosa sentencia, ciertamente una de las más infames, en la teoría política alemana” (traducción mía).

41 Véase Agamben (2007), p. 28.

42 Véase Tusseau (2011), p. 498 (traducción mía). 
titución de emergencia basada en el paradigma del Estado de Derecho ${ }^{43}$. Así, Dyzenhaus propugna un "proyecto de Estado de Derecho" ("rule-of-law-project") como capaz de responder a los estados de emergencia en tanto desafíos extremos al orden político y legal, proyecto que asigna un "rol importante" a los jueces -pero también a las ramas Legislativa y Ejecutiva-, que procura una "concepción sustantiva" antes que meramente formal, y que combate los "agujeros negros" y los "agujeros grises" legales que anulan la protección jurídica directamente o aparentando brindarla ${ }^{44}$.

Por su parte, Luigi Ferrajoli insiste en que es posible identificar las "condiciones de compatibilidad" del estado de excepción con el Estado de Derecho, para lo cual ha de llegarse a una inversión de la naturaleza de la figura, al menos tal como se la concibe de manera corriente, de tal suerte que "puede ser admitida como función de garantía cuando son rigurosamente preestablecidos sus presupuestos, sus contenidos y las instituciones competentes para su realización” ${ }^{45}$. En tal sentido, el estudioso italiano piensa que la Constitución debe disciplinar "un poder específico de garantía" contra la subversión y en defensa de la paz y los derechos fundamentales, bajo tres condiciones: (i) como función justamente de garantía, y no como función política o de gobierno; (ii) conforme a presupuestos precisos y contenidos rígidos previstos constitucionalmente; (iii) confiada a una institución de garantía secundaria, como un Tribunal Constitucional ${ }^{46}$.

Como quiera que fuere, parece claro que, en el marco del Estado constitucional y democrático de Derecho, los estados de excepción han de sujetarse a determinados criterios o principios orientadores. De especial relevancia parecen ser los once criterios enunciados por Clinton Rossiter en la obra que dedicó a la así llamada "dictadura constitucional". Tales criterios, que el profesor norteamericano consideró agrupables en tres categorías diferenciadas en función del momento de la emergencia (inicio, continuación y finalización), son los siguientes:

43 En la doctrina nacional, GonZÁLEs (1999), pp. 19-20, ha aseverado, erróneamente, que los estados de excepción acarrean la "negación temporal” o la "suspensión” del Estado de Derecho.

44 Véase Dyzenhaus (2006), pp. 17-19 y 200 (sobre el proyecto de Estado de Derecho); pp. 3, 123 y 166 (sobre los agujeros negros legales); y pp. 3, 42, 50, 205 y 210 (sobre los agujeros grises legales). Véase también Dyzenhaus (2005), pp. 34-37.

45 Véase Ferrajoli (2011), p. 101, t-II.

46 Ibíd., pp. 103 y 104-105. 
"Ni un régimen general ni una institución particular de la dictadura constitucional debe ser iniciado a menos que sea necesario o aun indispensable para la preservación del Estado y su orden constitucional".

"La decisión de instituir una dictadura constitucional nunca debe estar en las manos del hombre u hombres que constituirán el dictador".

"El gobierno no debe iniciar una dictadura constitucional sin adoptar una provisión específica para su culminación”.

"Todos los usos de poderes de emergencia y todos los reajustes en la organización del gobierno deben ser efectuados en procura de requerimientos legales o constitucionales".

"La institución dictatorial no debe ser adoptada, los derechos no deben ser invadidos, el procedimiento regular no debe ser alterado, si no es absolutamente necesario para resolver una crisis particular".

"Las medidas adoptadas en el marco de una dictadura constitucional nunca deben ser permanentes en carácter o efectos".

"La dictadura debe ser llevada por personas representativas de cada parte de la ciudadanía interesada en la defensa del orden constitucional existente".

"La responsabilidad última debe ser mantenida para cada acción adoptada bajo una dictadura constitucional".

"La decisión de terminar una dictadura constitucional, como la decisión de instituir una, nunca debe estar en las manos del hombre u hombres que constituyen el dictador".

"La dictadura constitucional no debe extenderse más allá de la culminación de la crisis para la cual fue instituida".

"La terminación de la crisis debe ser seguida por un retorno tan completo como sea posible a las condiciones políticas y de gobierno existentes antes de la iniciación de la dictadura constitucional" 47 .

Aunque es incuestionable que el cumplimiento de estas pautas mantendría al gobierno de crisis dentro del marco del Estado constitucional y democrático de Derecho, lo que parece realmente difícil (quizá imposible) es evitar que el estado de excepción devenga en la práctica en un régimen de abuso y opresión, o incluso, en casos extremos, en un régimen abiertamente tiránico ${ }^{48}$. De cualquier modo,

47 Véase Rossiter (2011), pp. 298-306 (traducción mía).

48 Véanse Agamben (2007), p. 34; Friedrich (1975), p. 610, t-II; Tusseau (2011), pp. 500 y 501; Keith y POE (2004), pp. 1071 y ss.; LeVINSON (2006), pp. 68-69. 
Giorgio Agamben ha sostenido que los once criterios de Rossiter pueden ser reducidos a los dos esenciales de necesidad y provisionalidad ${ }^{49}$. Quiere decir que solamente puede declararse el estado excepcional cuando es la única alternativa para enfrentar la emergencia y que siempre ha de tener alcance limitado en el tiempo.

Pese a que tampoco es posible detenerse aquí en la temática relativa a la aplicación de los principios de razonabilidad y proporcionalidad en el marco de los regímenes de excepción constitucional -temática asociada a la suspensión o restricción del ejercicio de los derechos fundamentales, que deberá ser objeto de estudio posterior-, es del caso recordar su reconocimiento constitucional (artículo 200, párrafo final) y su afirmación reiterada en la jurisprudencia del Tribunal Constitucional ${ }^{50}$ y en la doctrina constitucionalista, que consideran que estos principios son indispensables ${ }^{51}$.

\section{LA PROCLAMACión DEL ESTADO DE EMERGENCIA: EL MODELO DE LA AUTOINVESTIDURA}

Conforme al artículo 137.1 de la Constitución peruana de 1993, el órgano legitimado para declarar el estado de emergencia (como también el estado de sitio) es el Presidente de la República. Se trata, pues, de un acto de autoinvestidura, que parece más próximo a la tradición inglesa de la prerrogativa regia, recogida y adaptada por John Locke, que a la experiencia constitucional de la Europa continental que deriva del pensamiento de Montesquieu ${ }^{52}$.

No siempre fue así, sin embargo, ni en Perú ni en otros ordenamientos constitucionales. De hecho, un estudio comparativo de alcance mundial, sobre una muestra de 522 Constituciones que contemplaban el estado de emergencia entre los años 1850 y 2000, encuentra que el Poder Ejecutivo tuvo la facultad de declarar un estado de emergencia en sólo alrededor de 50\% de las Constituciones

\footnotetext{
49 Véase Agamben (2007), p. 35.

50 Véanse Sentencia del Tribunal Constitucional No 017-2003-AI-TC, de 16 de marzo de 2004, c. 18.g; Sentencia del Tribunal Constitucional No 00002-2008-AI, de 9 de septiembre de 2009, cs. 31.c y 32; Sentencia del Tribunal Constitucional No 00022-2011-PI/TC, de 8 de julio de 2015, cs. 395 y 397.

51 Véase Power (1990), pp. 115 y 273; Palacios (1988), pp. 50-51, 107, 110, 113-121, 137-139, 144-145 y 157-158; Eguiguren (1989), pp. 276-283 y 285-286; CAstillo (2005), pp. 9, 14-17 y 28-29.

52 Véase Siles (2017), pp. 18-19, 38 y 40.
} 
antes del año 1950, porcentaje que fue en aumento desde entonces y llegó a más de $80 \%$ en el año 200053 .

En suelo peruano, a lo largo del siglo XIX, las Constituciones otorgaron al Congreso de la República el poder de proclamar el estado de excepción ${ }^{54}$. Recién en el siglo XX, específicamente con la Carta de 1933, el Ejecutivo recibe la potestad de determinar por sí mismo si la "seguridad del Estado" exigía la "suspensión de garantías" (sólo de algunas de ellas, en realidad), total o parcialmente, y en todo o parte del territorio nacional (artículo 70) ${ }^{55}$. Las Constituciones posteriores, de 1979 y 1993, si bien optaron por una división del régimen de excepción en dos modalidades -estado de emergencia y estado de sitio, según se ha indicado antes en este artículo-, mantuvieron para cada una de ellas la facultad del Presidente de la República de proclamar el gobierno de crisis.

No obstante el segundo criterio o principio enunciado por Clinton Rossiter, conforme al cual la decisión de instaurar la "dictadura constitucional" no debe recaer en la misma persona que ejercerá los poderes extraordinarios ${ }^{56}$, parecen válidas las razones del constitucionalismo contemporáneo para permitir que sea el Gobierno, reconocido como más rápido y eficiente, y no el Parlamento, con sus complicados procedimientos y lentas deliberaciones, el que decida si la nación se halla ante una amenaza existencial. Esto es así, en particular, considerando un peligro tan grave y de acciones tan repentinas, como el representado por el terrorismo global, capaz de golpear brutalmente a los Estados de un momento a otro.

Vale la pena, sin embargo, tener en cuenta la primera experiencia histórica de dictadura constitucional, precisamente la originada en la República romana clásica. Y es que entonces el genio jurídico-político romano diseñó un modelo de hetero-investidura en el que la decisión sobre la existencia de la crisis correspondía al órgano ejecutivo ordinario, esto es, a los cónsules, quienes delegaban su poder en el hombre eminente que debían nominar como dictador (en ningún caso, los cónsules podían designarse a sí mismos). El Senado tenía entonces también una participación relevante, pues la práctica institucional llevó a que interviniera con una recomendación acerca de la cuestión de si existía o no una emergencia que

53 Véase Constitutional Design Group (2011), p. 5.

54 Véanse Coloma (1985), p. 55; Power (1990), pp. 133-139.

55 Véase Coloma (1985), p. 55.

56 Véase Rossiter (2011), p. 299. 
ameritase la instauración del régimen dictatorial orientado a salvar la Constitución ${ }^{57}$.

En la actualidad, no parece reproducible esta experiencia original, consistente en separar siempre a quien debe declarar la emergencia y quien debe ejercer los poderes extraordinarios destinados a conjurarla, en particular, si ambas autoridades han de ubicarse en el campo del Ejecutivo (el gobernante ordinario y el magistrado extraordinario). No obstante, sí parece posible estipular en la Constitución determinados supuestos, de especial gravedad, en los que distintos órganos puedan contrapesar la autoinvestidura del Ejecutivo, eventualmente incluso mediante el otorgamiento de autorización o consentimiento. Así, la intervención del Legislativo podría darse, ocasionalmente, en clave de acción coadyuvante (habría que estipular claramente los supuestos), pero siempre como medio de control de la proclamación de la emergencia (ex post).

De hecho, hoy en día, algunos ordenamientos que diferencian modalidades de estado de excepción, optan por distintas variantes respecto no sólo de los requisitos, efectos y duración de los estados excepcionales, sino también respecto de los órganos competentes para la declaración, en particular, asignando roles diversos a Ejecutivo y Legislativo. Así, por ejemplo, en España, el estado de alarma es declarado por el Gobierno con acuerdo del Consejo de Ministros, y lo mismo ocurre en el estado de excepción, pero en este caso se requiere autorización previa del Congreso de los Diputados, mientras que en el estado de sitio la declaración corresponde al Congreso (artículo 116, Const.) ${ }^{58}$. Algo semejante se observa en Colombia, donde las tres modalidades de estados de excepción permiten al Presidente de la República hacer la proclamación, con el consentimiento del gabinete ministerial, pero en la modalidad más grave -esto es, el estado de guerra exteriorhace falta en principio la previa autorización del Senado para la declaratoria de guerra (artículos 212-215, Const.).

El peligro de la autoinvestidura prevista para el estado de emergencia peruano (como también para el estado de sitio) es, desde luego, la posibilidad de un ejerci-

57 Sobre la hetero-investidura en el régimen dictatorial de la Roma republicana, véase SiLES (2014), pp. 414415. Véanse también Schmitt (1985), pp. 33-34; Rossiter (2011), pp. 19-21; Gross y Ní Aoláin (2006), pp. 19-20.

58 En esta línea de pensamiento, el profesor Pérez Royo (2010), p. 1040, considera que "[l]a declaración del estado de excepción debe ser una operación distinta orgánica y funcionalmente de la ejecución del derecho de excepción aplicable a dicho estado", añadiendo que "la primera debe corresponder al Parlamento", en tanto "la segunda al Gobierno". 
cio abusivo de esta potestad, sin que ni el Parlamento ni la judicatura alcancen a ejercer los controles adecuados de orden político y jurisdiccional, respectivamente. Pero tal peligro tiene que ver directamente con la apreciación de las circunstancias que habilitan la proclamación, es decir, con las causales que la Carta prevé para la introducción del régimen excepcional.

Como quiera que fuere, parece conveniente recordar que el Tribunal Constitucional peruano ha señalado, en la primera sentencia que emitió en la materia, con ocasión del proceso de inconstitucionalidad instaurado por la Defensoría del Pueblo contra la ley No 24.150, regulatoria de la participación de las Fuerzas Armadas en los estados de excepción cuando asumen el control del orden interno, que una de las características que distinguen al régimen excepcional es la existencia de controles tanto de orden jurisdiccional como de naturaleza política en sede parlamentaria, "para que se cumplan los principios de rendición de cuentas y de responsabilidad política"59. Este criterio ha sido luego confirmado por el Tribunal Constitucional en la reciente sentencia expedida en la causa ventilada sobre la constitucionalidad del Decreto Legislativo No 1095, relativo a las reglas de uso de la fuerza por las Fuerzas Armadas en el territorio nacional ${ }^{60}$.

Unos años antes, en el fallo dictado en el proceso de inconstitucionalidad seguido contra la Ley No 29.166, sobre las reglas de empleo de la fuerza por las Fuerzas Armadas dentro del territorio nacional, el supremo intérprete de la Constitución, siempre en la lógica de fortalecer los controles sobre el estado de excepción, había afirmado que "esta figura ha ido evolucionando con el fin de respetar el principio de equilibrio de poderes”, razón por la cual "la declaratoria exige una fundamentación (político-jurídica) y un progresivo sistema de rendición de cuentas, tanto en el ámbito jurisdiccional como en el político"61.

Es claro que tales controles -con especial énfasis, los de índole políticadebieran ser aplicados también sobre la proclamación del estado de emergencia (y, hablando en términos más amplios, de cualquier estado de excepción).

\footnotetext{
59 Véase Sentencia del Tribunal Constitucional No 017-2003-AI-TC, de 16 de marzo de 2004, fundamento jurídico 18.i.

60 Véase Sentencia del Tribunal Constitucional No 00022-2011-PI/TC, de 8 de julio de 2015, c. 351.

61 Véase Sentencia del Tribunal Constitucional No 00002-2008-AI, de 9 de septiembre de 2009, c. 21.
} 


\section{LA DEFINICIÓN DE LAS CAUSALES DEL ESTADO DE EMERGENCIA}

\section{VI.1. Indeterminación y necesidad de concreción de las causales}

La Constitución peruana de 1993, en reiteración textual de su antecesora de 1979, estipula que el Presidente de la República, con acuerdo del Consejo de Ministros, puede decretar el estado de emergencia "en caso de perturbación de la paz o del orden interno, de catástrofe o de graves circunstancias que afecten la vida de la Nación", mientras que el estado de sitio puede ser declarado, siempre por el primer mandatario de la nación, con acuerdo del gabinete ministerial, "en caso de invasión, guerra exterior, guerra civil, o peligro inminente de que se produzcan” (artículo 137).

Décadas antes, la Carta de 1933 había optado por una significativa indeterminación del supuesto habilitante, pues su artículo 70 apenas se refería a "cuando lo exija la seguridad del Estado", de tal suerte que, como indica Palacios Mc Bride, se trataba de una causal "demasiado amplia" y que permitía al Ejecutivo incurrir en arbitrariedades represivas ${ }^{62}$. Por contraste con esta regulación escueta y ambigua, estudiosos como Coloma Marquina, Eguiguren Praeli, Rubio Correa y Bernales Ballesteros, encontraron un avance en la enumeración de causales contenida en la Constitución de 197963, luego repetida en la de 1993.

No obstante, y aun cuando puede convenirse en que hay mayor precisión en los supuestos habilitantes previstos en las Constituciones de 1979 y 1993 por comparación con la de 1933, se trata siempre de conceptos indeterminados ${ }^{64}$ y por ello de contenido variable y ciertamente polémico. De hecho, el propio Coloma Marquina, en el caso del estado de emergencia, estima que en el texto constitucional "no hay cuidado en definir qué se entiende por perturbación de la paz interna, o a qué tipo de graves circunstancias se hace referencia" 65 . También Rubio y Bernales opinan que, aun cuando existen causales "objetivables con relativa facilidad" (como las de catástrofe, invasión y guerra exterior), otras, sin embargo, resultan ambiguas y pueden dar lugar a un régimen dictatorial injustificado, como sucede, respecto del estado de emergencia, con el caso de "perturbación de la paz o del orden interno" y las "graves circunstancias que afecten la vida de

\footnotetext{
62 Véase Palacios (1988), pp. 63-64. Véase también Rubio y Bernales (1983), p. 217.

63 Véanse Coloma (1985), p. 86; Eguiguren (1989), p. 265; Rubio y Bernales (1983), pp. 217-218.

64 Véase Bernales (1999), p. 612.

65 Véase Coloma (1985), p. 77.
} 
la Nación", y, respecto del estado de sitio, con los supuestos de "guerra civil" y "peligro inminente" 66.

Lo que explicaría la existencia de estos enunciados de contenido abierto en la Carta Fundamental es que, al parecer, la Constituyente de 1979, acogiendo el punto de vista del asambleísta Roberto Ramírez del Villar, procuró establecer las causales de los estados de excepción de un modo general, a fin de no obstaculizar la defensa del Estado ${ }^{67}$. Criterio que, como se ha indicado, mantuvo el Congreso Constituyente Democrático, autor de la Carta de 1993.

Lamentablemente, la jurisprudencia constitucional peruana no ha brindado la mayor precisión conceptual que se requiere para dotar de concreción a las causales del estado de emergencia -única modalidad de régimen de excepción aplicada hasta ahora bajo las Cartas Fundamentales de 1979 y 1993-, en particular de cara a casos concretos. Más bien, el Tribunal Constitucional, en el marco de sus potestades de control abstracto de constitucionalidad, se ha inclinado por exhortar al Congreso de la República a aprobar un marco normativo sobre los regímenes de excepción previstos en el artículo 137 de la Constitución, en armonía con el artículo 27 de la Convención Americana sobre Derechos Humanos (CADH), marco normativo que, según el parecer del alto tribunal, debe ofrecer "un desarrollo de los conceptos de perturbación de la paz, del orden interno, de catástrofe o de graves circunstancias que afecten la vida de la Nación para establecer los casos y situaciones que ameritan la declaratoria del estado de emergencia"68.

En la práctica constitucional peruana existe, desde luego, gran laxitud en la invocación y aplicación de las causales del estado de emergencia consagradas en el artículo 137.1 de la Constitución. Así, en la actualidad, es frecuente que sean declaradas en estado de emergencia diversas zonas del país para enfrentar problemas como la violencia subversiva y terrorista de los remanentes de Sendero Luminoso, al parecer asociados con bandas de narcotráfico, en el VRAEM ${ }^{69}$, y la violencia desatada por peligrosas bandas dedicadas a la delincuencia común (asalto a mano armada, secuestro y extorsión, narcotráfico, sicariato), en las provincias del Santa

66 Véase Rubio y Bernales (1983), pp. 218-219. Véase también Bernales (1999), pp. 614-615.

67 Véase Palacios (1988), pp. 68-69.

68 Véase Sentencia del Tribunal Constitucional No 00002-2008-AI, de 9 de septiembre de 2009, punto resolutivo 6 y c. 31.a. Otros estudiosos y actores institucionales coinciden en la recomendación de aprobar una ley integral sobre estados de excepción. Véanse Power (1990), p. 277; Defensoría del Pueblo (2003), p. 151; CVR (2003), p. 522, t-VI.

69 Véanse Decreto Supremo No 031-2017-PCM (2017); Decreto Supremo No 032-2017-PCM (2017). 
y Casma (departamento de Áncash) ${ }^{70}$ y en la Provincia Constitucional del Callao ${ }^{71}$. Por cierto, la proclividad de las autoridades nacionales para la declaración del estado de emergencia, a lo largo de la historia, sobre la base de evaluaciones más bien permisivas de las circunstancias que la justifican, ha sido observada por los estudiosos de la materia ${ }^{72}$.

\section{VI.2. La exigencia de afectación a la vida de la nación}

Una de las cuestiones más difíciles relacionadas con las causales del estado de emergencia es la determinación de la gravedad que deben revestir las circunstancias que habilitan a declarar la situación excepcional. A falta de elementos de contenido más precisos en la legislación y jurisprudencia nacionales, cabe acudir a diversas fuentes del Derecho Internacional de los Derechos Humanos (normativas, jurisprudenciales y doctrinales), así como también a la doctrina constitucionalista.

Interesa, en particular, establecer el alcance de la exigencia de afectación de la vida nacional, incluida en la enumeración de causales que contiene el primer párrafo del artículo 137.1 de la Carta peruana vigente. Sobre este punto, caben al menos dos interpretaciones. La primera es que tal exigencia sólo se refiere a la expresión "graves circunstancias", la cual constituye una causal separada e independiente de los casos de "perturbación de la paz o del orden interno" y de "catástrofe". La segunda interpretación posible es que el requisito de afectar la vida de la nación califique también a las dos primeras causales, esto es, a los casos de "perturbación de la paz o del orden interno" y de "catástrofe", además del caso de "graves circunstancias".

Si bien el tenor literal del enunciado constitucional parece sugerir que la interpretación adecuada sería la primera, una labor interpretativa más elaborada y comprehensiva del texto constitucional lleva a una conclusión distinta, a favor de la segunda lectura de las causales. Ante todo, parece claro para la doctrina y jurisprudencia constitucionales que la interpretación literal es limitada e insuficiente, por lo que no puede ser nunca el único criterio o el prevaleciente entre varios, cuando el intérprete se halla ante la tarea de fijar el contenido y alcance de una

\footnotetext{
70 Véase decreto supremo No 019-2017-PCM (2017).

71 Véase decreto supremo No 036-2017-PCM (2017).

72 Véase Rojas (1985), p. 44 y ss.; García-Sayán (1987), p. 96; Power (1990), p. 274; Siles (2015), pp. 79-80.
} 
cláusula constitucional73. Pero hay también otros dos elementos que refuerzan la opción por la segunda interpretación, a saber, las obligaciones impuestas en esta materia por el Derecho Internacional de los Derechos Humanos (DIDH), y el consenso de la doctrina constitucional.

En efecto, los dos principales tratados internacionales sobre derechos humanos vigentes en el Perú permiten suspender ciertas obligaciones internacionales en virtud de la configuración de un estado de excepción, pero para ello debe existir lo que antes se ha denominado aquí una "amenaza existencial". El Pacto Internacional de Derechos Civiles y Políticos (PIDCP) señala en su artículo 4 que los supuestos habilitantes son los de "situaciones excepcionales que pongan en peligro la vida de la nación", mientras que la Convención Americana sobre Derechos Humanos $(\mathrm{CADH})$ regula en su artículo 27.1 que deberá estarse ante un "caso de guerra, de peligro público o de otra emergencia que amenace la independencia o seguridad del Estado Parte".

Qué debe entenderse por esta amenaza existencial o situación excepcional que se cierne sobre la vida de la nación o que parece estar a punto de disolver la comunidad política mediante una guerra u otro supuesto de similar gravedad, viene determinado por el propio DIDH. Y, como se sabe, el DIDH forma parte del Derecho Constitucional peruano, pues integra el denominado "bloque de constitucionalidad", con lo que los jueces nacionales, incluyendo al Tribunal Constitucional, están obligados a cumplir los tratados en vigor, a los que se les reconoce rango constitucional, y la jurisprudencia de los órganos de la jurisdicción internacional de derechos humanos, en virtud de una interpretación unitaria de la Cuarta de las Disposiciones Finales y Transitorias y de los artículos 55, 3, 57 y 205 de la Constitución, así como del artículo V del Título Preliminar del Código Procesal Constitucional ${ }^{74}$.

De especial relevancia resulta, entonces, la sentencia emitida por la Corte Interamericana de Derechos Humanos (corte IDH) en el Caso Zambrano Vélez y otros vs. Ecuador, pues, siguiendo jurisprudencia de su homólogo europeo, la Corte Interamericana sostiene que "para que se justifique un estado de excepción es necesario: a) que exista una situación excepcional de crisis o emergencia;

73 Véanse Landa (2003), pp. 486, 488 y 495-496; Hesse (2012), pp. 61-63 y 67-69; GUASTini (2001), pp. 263-264. Véase también Sentencia del Tribunal Constitucional No 5854-2005-AA, de 8 de noviembre de 2005 , cs. $12,17,32$ y 36 .

74 Véanse HaKansson (2009), pp. 180 y 234-238; Landa (2006), pp. 119-121. Véase también Sentencia del Tribunal Constitucional No 2730-2006-PA/TC, de 21 de julio de 2006, cs. 9-15. 
b) que ésta afecte a toda la población, y c) que constituya una amenaza a la vida organizada de la sociedad"75.

$\mathrm{Al}$ respecto, debe destacarse que la jurisprudencia del Tribunal Europeo de Derechos Humanos (TEDH o ECHR por sus siglas en inglés) sobre el significado de la frase "otro peligro público que amenace la vida de la nación", contenida en el artículo 15.1 de la Convención Europea sobre Derechos Humanos (CEDH), a que se remite la Corte IDH, es aún más explícita y detallada, manteniéndose constante desde el primer fallo, expedido en el Caso Lawless vs. Ireland, el 1 de julio de 1961. En efecto, en esta ocasión el TEDH aseveró que "el significado natural y habitual de las palabras 'otro peligro público que amenace la vida de la nación' es suficientemente claro" y que tales palabras "se refieren a una situación excepcional de crisis o emergencia que afecta a toda la población y constituye una amenaza a la vida organizada de la comunidad que compone el Estado"76. Tales criterios han sido reiterados en pronunciamientos posteriores, como por ejemplo el dictado por el TEDH en el Caso A. and Others vs. The United Kingdom $(2009)^{77}$, que es incluso posterior a la decisión adoptada por la Corte IDH en el Caso Zambrano Vélez y otros vs. Ecuador (2007).

Es pertinente citar también, en idéntico sentido, dos importantes informes institucionales elaborados en el marco de las actividades de los órganos de la Organización de las Naciones Unidas (ONU) encargados de brindar protección internacional a los derechos humanos. Así, el Informe de Leandro Despouy, quien fue Relator Especial sobre los Derechos Humanos y los Estados de Excepción, designado por la Comisión de Derechos Humanos y la Subcomisión de Prevención de Discriminaciones y Protección de Minorías de las Naciones Unidas, entiende por "situaciones de emergencia" a todas aquellas que "resultan de una crisis grave que afecte al conjunto de la población y que ponga en peligro la existencia misma de la comunidad organizada sobre la base del Estado (énfasis en el original)", concepto que, en su opinión, es la interpretación más próxima a las nociones de "peligro público" o de "situaciones excepcionales" previstas en el PIDCP (artículo 4), la $\mathrm{CEDH}$ (artículo 15) y la CADH (artículo 27)78.

\footnotetext{
75 Véase Corte IDH, Serie C No 166, de 4 de julio de 2007, párr. 46.

76 Véase STEDH, Case of Lawless vs. Ireland, de 1 de julio de 1961, par. 28 (traducción mía).

77 Véase STEDH, Case of A. and Others vs. United Kingdom, 19 de febrero de 2009, par. 176.

78 Véase Despouy (1999), p. 18.
} 
Por su parte, y todavía con mayor detalle y exhaustividad, el Informe elaborado por Nicole Questiaux, anterior Relatora Especial de los mismos órganos de las Naciones Unidas, encargada de elaborar un Estudio sobre las Implicaciones para los Derechos Humanos de los Recientes Desarrollos Concernientes a las Situaciones Conocidas como Estados de Sitio o Emergencia, aseveró que "la situación de peligro debe afectar, de un lado, al conjunto de la población, y, del otro, ya sea al conjunto del territorio (siendo este, a fortiori, el caso en una situación de guerra externa tal como está previsto, por ejemplo, bajo las Convenciones Interamericana y Europa), o ya sea a ciertas partes del mismo"79.

Más interesante aún, el Informe Questiaux añade que "debe haber una amenaza a la propia existencia de la nación, es decir, a la vida organizada de la comunidad que constituye la base del Estado, si esto significa la integridad física de la población, la integridad territorial o el funcionamiento de los órganos del Estado" 80 .

En fin, los "Principios de Siracusa sobre las Disposiciones de Limitación y Derogación del Pacto Internacional de Derechos Civiles y Políticos”, de manera amplia y comprehensiva, estipulan que una situación constituye una "amenaza a la vida de la nación" cuando:

“a) Afecte a toda la población y a todo el territorio del Estado o a parte de él, y

b) Amenace la integridad física de la población, independencia política o la integridad territorial del Estado o la existencia o el funcionamiento básico de instituciones indispensables para asegurar y proteger los derechos reconocidos en el Pacto"81.

Los "Principios de Siracusa", que en la temprana opinión de Diego GarcíaSayán constituyen "la más consistente interpretación de las normas del Pacto [PIDCP] sobre régimen de excepción" 82 , precisan asimismo que "el conflicto interno y la agitación que no representen una amenaza grave e inminente a la vida de la nación no pueden justificar las derogaciones en virtud del artículo 4”

79 Véase Questiaux (1982), $\$ 55.3$ (traducción mía).

80 Ibid., $\$ 55.4$ (traducción mía).

81 Véase GarCíA-SAYÁn (1987), p. 285. Este autor transcribe los "Principios de Siracusa" como Anexo I de su libro (pp. 277-295). Puede consultarse la versión en inglés de los "Principios de Siracusa" en United Nations Economic and Social Council UN Sub-Commission on Prevention of Discrimination and Protection of Minorities (1985), pp. 3-14.

82 Véase García-Sayán (1988), p. 108. 
y que "las dificultades económicas por sí solas no pueden justificar las medidas de derogación" 83 .

De modo complementario, ha de tenerse en cuenta la más reciente Observación General No 29 (2001), sobre los "estados de excepción y suspensión de derechos", emitida por el Comité de Derechos Humanos creado por el PIDCP, la cual confirma que es una "condición fundamental" el que la situación excepcional "ponga en peligro la vida de la nación", aclarando que "no todo disturbio o catástrofe constituye una situación excepcional que ponga en peligro la vida de la nación, como se exige en el párrafo 1 del artículo $4 " 84$.

En parecidos términos se expresa la doctrina del DIDH y del Derecho Constitucional. Así, Amaya Úbeda de Torres, junto con señalar que los convenios internacionales de derechos humanos parten de una noción mixta de estado de emergencia, que combina aspectos formales y cualitativos o de fondo, plantea una definición del mismo como situación que "amenaza la existencia organizada de un pueblo, es decir, el sistema político y social del que éste dispone como Estado" 85 . Lo mismo cabe decir de la doctrina del Derecho Constitucional, pues Castillo Córdova opina que las circunstancias justificativas del estado de excepción han de suponer "un serio riesgo para la normal existencia y desenvolvimiento de la comunidad estatal y de su institucionalidad", mientras Bernales Ballesteros señala que ha de tratarse de "situaciones excepcionales, de extrema gravedad, que amenazan la continuidad del Estado y de la sociedad" 86 .

En definitiva, entonces, parece claro que la interpretación adecuada de la configuración de las causales del estado de emergencia constitucional en Perú supone que, en cada caso, ha de estar en peligro la vida de la nación, pues ésta es una exigencia contenida en el PIDCP y la $\mathrm{CADH}$-y, en términos más generales, en el DIDH, incluyendo sus desarrollos jurisprudenciales y doctrinales-, exigencia que debe entenderse que forma parte del bloque de constitucionalidad, por lo que los jueces nacionales, incluyendo al Tribunal Constitucional, están obligados a cumplirla y a hacerla cumplir.

\footnotetext{
83 Véase García-Sayán (1987), p. 285.

84 Véase Comité de Derechos Humanos (2001), párr. 2-3.

85 Úbeda (2007), p. 581. Véanse también, Faúndez (2004), p. 99; O’Donnell (1989), pp. 398-403.

86 Véanse Castillo (2005), p. 5; Bernales (1999), p. 611. Véase también Espinosa-Saldaña (2003), pp. 172-174.
} 
Esta conclusión, desde luego, parece descalificar el actual recurso a la declaración de estados de emergencia que se hace en el país, para enfrentar los casos de los remanentes de Sendero Luminoso en el VRAEM (distritos y provincias de los departamentos de Ayacucho, Huancavelica, Junín y Cusco), y la problemática de la delincuencia común en las provincias del Santa y Casma, del departamento de Áncash, y en la Provincia Constitucional del Callao, antes referidos. En efecto, en estos casos, conforme a lo aquí expuesto, es claro que no se llenan los requisitos que configuran una amenaza existencial o peligro para la vida de la nación.

\section{LA CUESTIÓN DE LA TEMPORALIDAD DEL ESTADO DE EMERGENCIA}

Una cuestión de primer orden es la que atañe a la sujeción del estado de emergencia al principio de temporalidad o transitoriedad ${ }^{87}$, que, como se ha tenido ocasión de exponer aquí, es consustancial al régimen de excepción constitucional. Ocurre, sin embargo, como también ha sido explicado, que su uso, más bien frecuente, tiende a configurar un estado de "normalización de la emergencia" o "permanencia de la excepcionalidad", con los consiguientes efectos nocivos, de erosión del Estado de Derecho, que de allí derivan.

El primer límite en la dimensión temporal, desde luego, viene indicado por el propio texto constitucional, el cual establece que la instauración del estado de emergencia no podrá exceder de sesenta días, si bien es prorrogable mediante la aprobación de un nuevo decreto por el Presidente de la República, con el voto conforme del Consejo de Ministros. Dos problemas surgen, empero, con esta regulación constitucional, a saber, lo dilatado del plazo, de un lado, y la posibilidad de renovarlo sucesivamente, del otro.

En cuanto a la duración excesiva del plazo, un primer aspecto que debe ser destacado es que su fijación se habría producido de manera irregular. La Carta de 1933 previó que la "suspensión de garantías", antecedente directo del estado de emergencia constitucionalizado en $1979^{88}$ y mantenido en 1993, podía decretarse hasta por un máximo de treinta días (artículo 70 de la Constitución de 1933). La intención inicial en el seno de la Asamblea constituyente de 1979 fue conservar ese plazo y así lo aprobó el Plenario, pese a lo cual la Comisión de Redacción, que carecía de competencia legal para cambiar el contenido de las

87 Véanse Castillo (2005), p. 9; Bernales (1999), p. 613. Véase también Sentencia del Tribunal Constitucional No 017-2003-AI-TC, de 16 de marzo de 2004, c. 18.d.

88 Véanse Rubio y Bernales (1983), p. 217; Chirinos (1984), p. 261. Véase también Coloma (1985), p. 76. 
cláusulas aprobadas por el Pleno, introdujo de manera subrepticia la duplicación del plazo, votando luego la Asamblea, sin advertir la modificación, en el sentido de confirmar el texto con el nuevo plazo duplicado ${ }^{89}$.

Justamente, la extensión del período del estado de emergencia hasta un máximo de sesenta días, y del estado de sitio hasta cuarenta y cinco días, fue uno de los elementos que llevó a Eguiguren Praeli a considerar que la Carta de 1979 resultaba más represiva que su antecesora de $1933^{90}$.

Pero más grave que la consagración constitucional de un plazo dilatado para el estado de emergencia resulta, sin embargo, la admisión de sucesivas renovaciones. Diversos autores, inclusive estando de acuerdo con la existencia del principio de temporalidad de los regímenes de excepción, aceptan que la Constitución no impone límites a las prórrogas sucesivas ${ }^{91}$.

De hecho, la práctica constitucional peruana conduce a prolongados períodos de excepcionalidad declarados y prorrogados por las autoridades competentes en distintos ámbitos del territorio nacional, a la vez que admitidos y convalidados, siquiera de manera pasiva u omisiva, por los órganos encargados de ejercer funciones de control (control político en el caso del Parlamento, control jurisdiccional en el caso de los jueces, incluyendo al Tribunal Constitucional).

Ahora bien, ¿̨cómo hacer para evitar que esta mala práctica constitucional siga distorsionando el modelo de régimen excepcional y, en general, el Estado constitucional y democrático de Derecho en el Perú? Una primera medida, bastante fácil desde un punto de vista teórico (más complicada desde una perspectiva política), consiste en introducir ciertas reformas constitucionales. En primer término, podría reducirse el plazo, aunque la duración del mismo será siempre discutible (sin contar con que, decretado el estado de emergencia con un plazo señalado, el régimen excepcional podría concluir antes si es que las condiciones que lo justificaban desaparecen o son eficaces los medios para conjurar la emergencia) ${ }^{92}$.

\footnotetext{
89 Véanse García-Sayán (1987), p. 110; Palacios (1988), pp. 82-83. Power (1990), p. 158, transcribe el texto del proyecto salido de la Comisión Principal (artículo 306), donde consta el plazo inicial de treinta días.

90 Véase Eguiguren (1989), p. 265.

91 Véanse Rubio (1999), p. 479, t-IV; Palacios (1988), p. 84.

92 En la historia constitucional, es célebre el caso de Lucio Quincio Cincinato, ilustre patricio romano dedicado a la agricultura, quien fue nombrado dictador en el año 458 A.C., y declinó el cargo tan pronto cumplió, en el curso de dos semanas, la misión de derrotar al enemigo que amenazaba con conquistar Roma, por lo que depuso las armas para volver a tomar sus instrumentos de labranza. Véanse Gross y Ní Aoláin (2006), pp. 25-26; Gross (2005), pp. 2-3; Rossiter (2011), p. 16. Véase también Siles (2014), p. 416.
} 
Más interesante resulta la posibilidad de una ley de enmienda constitucional que refuerce el control político del Parlamento sobre la renovación del estado de emergencia. Como propone Power Manchego-Muñoz, la Constitución podría prever la necesidad de que la representación nacional confirme el decreto de prórroga, en particular considerando que, a diferencia de lo que sucede con la proclamación, en la prórroga ya no se está ante un hecho imprevisto y repentino que exige una actuación inmediata del Poder Ejecutivo, la cual no puede aguardar a las usualmente lentas y complejas deliberaciones parlamentarias ${ }^{93}$. Esta propuesta, por lo demás, retoma una similar presentada en la Constituyente de 1979 por los asambleístas Diez Canseco y Malpica ${ }^{94}$.

Incluso podría pensarse en una adaptación, en clave nacional, de la "escala creciente de mayorías” en la que piensa Bruce Ackerman como el medio más apropiado de una "Constitución de emergencia" que permita una respuesta adecuada frente al desafío del terrorismo global y sus demenciales ataques contra la población civil, como el perpetrado el 11 de septiembre de 2001 en suelo estadounidense. Conforme a este modelo, el Ejecutivo estaría facultado para actuar por sí solo únicamente durante "un período brevísimo", de una o dos semanas, apenas el tiempo necesario para que el Parlamento sesione y determine la acción a seguir. Tras una primera autorización por un período de dos o tres meses, la continuación del estado excepcional "debería requerir mayorías cualificadas cada vez más amplias", tal como "el apoyo de un 60 por 100 de los congresistas para una primera prórroga, un 70 por 100 para la sucesiva, y de un 80 por 100 para cada nueva extensión"95.

Como quiera que fuese, y aun si por ahora resultara impracticable una reforma constitucional sobre el estado de emergencia en el Perú, cabe la posibilidad de introducir mejoras sobre la mala práctica relativa a la renovación permanente de esta forma de anormalidad constitucional, mediante la actividad del legislador ordinario y de la jurisdicción constitucional.

Hay que lamentar de nuevo que la jurisprudencia del Tribunal Constitucional haya sido parca y reticente, omitiendo hacer precisiones también sobre el alcance del principio de temporalidad en el marco del régimen de excepción. En su primera sentencia en la materia (agosto de 2004) el supremo intérprete de la

93 Véase Power (1990), pp. 172 y 276.

94 Véanse Palacios (1988), pp. 83-84; Power (1990), p. 157.

95 Véase Ackerman (2007), pp. 110-111. Véase también Benazzo (2004), p. 85. 
Constitución se refirió a la "transitoriedad" como una característica distintiva del régimen excepcional, mencionando el fenómeno de su "prolongación indebida e inexcusable", pero sin señalar límite alguno a su renovación continua ${ }^{96}$. Cinco años después (septiembre de 2009), en la exhortación que dirige al Congreso de la República al concluir el proceso sobre la constitucionalidad de la ley No 29166, el Tribunal Constitucional solicita la aprobación de una ley que se ocupe del "plazo de 60 días establecido en el artículo 137 de la Constitución y la naturaleza excepcional de esta medida" 97.

Así, pues, atendiendo a la naturaleza justamente excepcional del estado de emergencia, el legislador democrático podría establecer que su renovación quedará sujeta al principio de mayorías crecientes para la prórroga, o, seguramente más osado pero necesario, que debe haber un tope o un número límite para las renovaciones sucesivas, ya que, por definición, la "Constitución de reserva" 98 no puede volverse permanente.

También parece posible, por cierto, que sea la jurisprudencia del Tribunal Constitucional la que establezca estas limitaciones mediante su labor interpretativa a la luz de los casos que le toca resolver en ejercicio de sus poderes de control de constitucionalidad.

A la luz de lo aquí expuesto queda claro, entonces, que las prórrogas sucesivas del estado de emergencia desvirtúan el modelo constitucional de estado de emergencia, y con ello el mismo Estado constitucional y democrático de Derecho. Por ello, es necesario corregir la mala práctica de sus prórrogas continuas, bastante frecuente y consolidada en el país, que consagra la normalización de la emergencia o permanencia de lo excepcional. Tales correcciones pueden realizarse mediante leyes de enmienda constitucional, o también mediante leyes de desarrollo aprobadas por el legislador ordinario, o, en fin, mediante la tarea interpretativa del Tribunal Constitucional.

\footnotetext{
96 Véase Sentencia del Tribunal Constitucional No 017-2003-AI-TC, de 16 de marzo de 2004, c. 18.d.

97 Véase Sentencia del Tribunal Constitucional No 00002-2008-AI, de 9 de septiembre de 2009, punto resolutivo 6 y c. 31.b.

98 Véase Benazzo (2004), p. 32. Cruz (1980), p. 12; (1984), p. 19, por su parte, se refiere a un "ordenamiento de reserva" y a una "Constitución alternativa de emergencia".
} 


\section{CONCLUSIONES}

1) El estado de emergencia ha sido usado con frecuencia en Perú, desde que fuera recogido por primera vez a nivel constitucional en la Carta de 1979. Ha dado lugar a numerosos abusos, de los cuales los más graves son los cometidos bajo su amparo durante la guerra interna que asoló al país durante las dos últimas décadas del siglo pasado.

Pero aun después, y hasta la actualidad, se observan distorsiones y malas prácticas en su aplicación por las autoridades, como ocurre en los casos del VRAEM (distritos y provincias de Ayacucho, Huancavelica, Junín y Cusco), El Santa y Casma (Áncash), y El Callao.

Se requiere, por ello, tal como han recomendado la Comisión de la Verdad y Reconciliación (CVR) y otros estudiosos y actores institucionales, una ley que regule de manera integral y comprehensiva $-\mathrm{y}$ más clara y precisa- el estado de emergencia, y, en general, el régimen de excepción constitucional.

2) Sería mejor que la Constitución previera tres y no sólo dos modalidades de estados de excepción. El actual estado de emergencia debiera dividirse en dos formas o modalidades: el estado de alarma, para supuestos de catástrofe (terremotos, inundaciones, sequías, crisis sanitarias, etcétera); y el estado de emergencia propiamente dicho, para hipótesis de amenaza existencial de origen político-social (subversión y terrorismo, por ejemplo) que no configuran causal de estado de sitio.

3) Existen un conjunto de principios que deben orientar la proclamación del estado de emergencia y el ejercicio de los consiguientes poderes extraordinarios por el Ejecutivo. Entre ellos, destacan dos que resultan esenciales y que, en cierto modo, compendian a todos los demás: el de necesidad y temporalidad (o transitoriedad).

Se sigue de esto, desde luego, que durante el estado de emergencia el Estado constitucional y democrático de Derecho no desaparece.

4) En relación a la proclamación del estado de emergencia, la Constitución peruana acoge el modelo de la autoinvestidura del Poder Ejecutivo, de manera que resulta conveniente diseñar mecanismos de contrapeso institucional a los poderes incrementados del Gobierno. En tal sentido, parece aconsejable reforzar el rol de control político que corresponde al Congreso de la República, lo que puede hacerse previendo que determinados supuestos, de especial gravedad, requerirán la aprobación previa de la representación nacional o que la declaración corresponderá directamente a ésta (tal como ocurre en los ordenamientos constitucionales de España y Colombia). 
5) La indeterminación del contenido de las causales del estado de emergencia, mantenida por la abstención del legislador democrático y del Tribunal Constitucional, llevan a considerar como un elemento de especial relevancia al Derecho Internacional de los Derechos Humanos, el cual ha establecido con rigor que una exigencia indispensable para la proclamación y mantenimiento de un estado de excepción es que exista una amenaza existencial o peligro para la vida de la nación.

Tal peligro se presenta siempre que "afecte a toda la población" y constituya una "amenaza a la vida organizada de la sociedad", según ha establecido, a la luz de diversos e importantes antecedentes en los sistemas universal y europeo de protección de los derechos humanos, la Corte Interamericana de Derechos Humanos en el Caso Zambrano Vélez y otros vs. Ecuador (2007).

6) La práctica de prórrogas sucesivas del estado de emergencia va contra la propia naturaleza temporal de la institución y erosiona los supuestos básicos del mismo orden constitucional. Por esta razón, no debe ser permitida, pues lleva al fenómeno de la "normalización de la emergencia" o "permanencia de la excepcionalidad", con sus consiguientes efectos nocivos.

Entre las medidas de corrección posible está el conceder al Congreso de la República la potestad de autorizar la prórroga, así como la adopción de un sistema de "mayorías crecientes" en el Parlamento para la renovación sucesiva de la emergencia constitucional.

\section{BiBLIOGRAFÍA CITADA}

Abad Yupanqui, Samuel (2004): Derecho Procesal Constitucional (Lima, Gaceta Jurídica).

Ackerman, Bruce (2007): Antes de que nos ataquen de nuevo: la defensa de las libertades en tiempos de terrorismo (Barcelona, Península).

Agamben, Giorgio (2007): Estado de excepción (Buenos Aires, Adriana Hidalgo Editora).

Aljovín de Losada, Cristóbal (2000): Caudillos y constituciones: Perú 1821-1845 (Lima, IRA-PUCP-FCE).

BAÑo LeÓN, José María (2013): "Carl Schmitt: la autoridad del poder" (estudio preliminar), en Schmitt, Carl, Ensayos sobre la dictadura 1916-1932 (Madrid, Tecnos), pp. XIII-LVI.

Basombrío Iglesias, Carlos y Rospigliosi, Fernando (eds.) (2006): La seguridad $y$ sus instituciones en el Perú a inicios del siglo XXI: reformas democráticas o neomilitarismo (Lima, IEP). 
BenAZzO, Antonella (2004): L'emergenza nel conflitto fra libertà e sicurezza (Torino, G. Giappichelli Editore).

Bernales Ballesteros, Enrique (1999): La Constitución de 1993. Análisis comparado, quinta edición (Lima, Constitución y Sociedad - ICS - RAO Editora).

BüHLER, Ottmar (2010): “Texto de la Constitución alemana de agosto de 1919 y comentario sistemático a sus preceptos", en A.A.V.V., La Constitución de Weimar (Madrid, Tecnos), pp. 115-358.

CASTILlo CóRdOVA, Luis (2005): ¿Se suspenden o restringen realmente los derechos constitucionales? Especial referencia a los procesos constitucionales en los regímenes de excepción (Piura: Universidad de Piura).

Chirinos Soto, Enrique (1984): La nueva Constitución al alcance de todos, tercera edición (Lima, AFA Editores).

Coloma Marquina, José (1985): El régimen de excepción en la Constitución peruana de 1979 y derechos humanos (tesis de bachillerato en Derecho, Lima, PUCP).

Comité de Derechos Humanos (2001): Observación General No 29, sobre el artículo 4 del Pacto Internacional de Derechos Civiles y Políticos: estados de excepción y suspensión de derechos (documento CCPR/C/21/Rev.1/Add.11, de 31 de agosto de 2001).

COMISIÓN de la Verdad y ReCONCILIACIÓN (CVR) (2003): Informe Final (Perú: 1980-2000) (Lima, CVR), tomos I, III, VI, VIII y IX.

Comisión Especial del Senado sobre las Causas de la Violencia y Alternativas de Pacificación en el Perú (1989): Violencia y pacificación (Lima, DESCO - CAJ).

Constant, Benjamin (2006): Curso de Politica Constitucional (Granada, Editorial Comares).

Constitutional Design Group (2011): State of Emergency, options report [Disponible en: http://www.constitutionmaking.org].

Cruz Villalón, Pedro (1980): El estado de sitio y la Constitución: la constitucionalización de la protección extraordinaria del Estado (1789-1978) (Madrid, CEC).

Cruz Villalón, Pedro (1984): Estados excepcionales y suspensión de garantías (Madrid, Tecnos).

Defensoría del Pueblo (2003): Restricción de derechos en democracia. Supervisando el Estado de emergencia (Informe Defensorial No 76, Lima, Defensoría del Pueblo).

Delgado-Guembes, César (2012): Manual del Parlamento: introducción al estudio del Congreso peruano (Lima, Congreso de la República). 
Despouy, Leandro (1999): Los derechos humanos y los estados de excepción (México D.F., IIJ-UNAM).

Donayre Montesinos, Christian (2006): "Fuerza militar y Constitución en Perú. Sobre las reglas para el uso de la fuerza y un análisis acerca de su constitucionalidad" en A.A.V.V., Memoria del X Congreso Iberoamericano de Derecho Constitucional, (Lima, PUCP - APDC - UNAM - IIDC - IDEMSA), tomo 2, pp. 175-191.

Dyzenhaus, David (2002): "The Permanence of the Temporary: Can Emergency Powers be normalized?” en Daniels, Ronald J., Macklem, Patrick y Roach, Kent (eds.), The Security of Freedom: Essay on Canada's Anti-Terrorism Bill (Toronto, University of Toronto Press), pp. 21-37.

Dyzenhaus, David (2005): "The State of Emergency in Legal Theory" en RamraJ, Victor, Hor, Michael y ROACH, Kent (eds.), Global Anti-Terrorism Law and Policy (Cambridge, Cambridge University Press), pp. 66-89.

Dyzenhaus, David (2006): The Constitution of Law. Legality in a Time of Emergency (Cambridge, Cambridge University Press).

Eguiguren Praeli, Francisco (1989): "El estado de emergencia y su aplicación en la Constitución peruana, 1980-1988” en A.A.V.V., La Constitución diez años después (Lima, Fundación Friedrich Naumann), pp. 263-287.

Espinosa-Saldaña Barrera, Eloy (2003): "Estados de excepción, control jurisdiccional y hábeas corpus. Experiencias y riesgos a la luz del caso peruano" en Id., Jurisdicción constitucional, impartición de justicia y debido proceso (Lima, ARA Editores), pp. 167-226.

Faúndez Ledesma, Héctor (2004): El Sistema Interamericano de Protección de los Derechos Humanos. Aspectos institucionales y procesales, tercera edición (San José, IIDH).

Ferrajoli, Luigi (2011): Principia Iuris. Teoría del derecho y de la democracia (Madrid, Editorial Trotta), tomo II.

Friedrich, Carl (1975): Gobierno constitucional y democracia (Madrid, Instituto de Estudios Políticos), tomo II.

García-Sayán Larrabure, Diego (1987): "Perú. Estados de excepción y su régimen jurídico” en García-Sayán Larrabure, Diego (ed.), Estados de emergencia en la región andina (Lima, CAJ), pp. 96-105.

García-Sayán Larrabure, Diego (1988): Hábeas corpus y estados de emergencia (Lima, CAJ).

GonZÁles OJedA, Magdiel (1991): La excepcionalidad en la Constitución: los estados de excepción y los derechos humanos en la legislación peruana (Lima, L.F. Lann). 
Grández Mariño, Agustín (2012): “¿Estamos frente a una desnaturalización del estado de emergencia?” en Actualidad Jurídica (No 222), pp. 205-211.

Gross, Oren (2005): The Concept of "Crisis": What Can We Learn from the Two Dictatorships of L. Quinctius Cincinnatus? (University of Minnesota Law School, Minnesota Legal Studies Research Paper, No 05-20).

Gross, Oren y Ní Aoláin, Fionnuala (2006): Law in times of crisis: emergency powers in theory and practice (New York, CUP).

GUASTINI, Riccardo (2001): “¿Peculiaridades de la interpretación constitucional?” en Id., Estudios de Teoría Constitucional (México, D.F., Fontamara), pp. 255278.

Hakansson Nieto, Carlos (2009): Curso de Derecho Constitucional (Lima, Palestra). Hesse, Konrad (2012): Escritos de Derecho Constitucional (Madrid, Fundación Coloquio Jurídico Europeo - CEPC).

Instituto de Defensa Legal (IDL) (2012): Informe. La criminalización de las protestas sociales durante el primer año del gobierno de Ollanta Humala. "De la gran transformación a la mano dura" (Lima, IDL).

Keith, Linda Camp y Poe, Steven C. (2004): "Are Constitutional State of Emergency Clauses Effective? An Empirical Exploration” en Human Rights Quarterly (Vol. 26, No 4), pp. 1071-1097.

Landa ARroyo, César (2003): Tribunal Constitucionaly Estado de Derecho, segunda edición (Lima, Palestra Editores).

Landa Arroyo, César (2006): "Implementación de las decisiones del sistema interamericano de derechos humanos en el ordenamiento constitucional peruano" en Id., Constitución y fuentes del Derecho (Lima, Palestra), pp. 117-132.

Lerner Febres, Salomón (2011): “¿Se aprendió la lección del conflicto armado interno?” en PÁSARA, Luis (ed.), Perú ante los desafios del siglo XXI (Lima, PUCP), pp. 49-73.

Levinson, Sanford (2006): "Preserving Constitutional Norms in Times of Permanent Emergencies" en Constellations (Vol. 3, No 1), pp. 59-73.

LeVInSON, Sanford y Balkin, Jack (2010): "Constitutional Dictatorship: Its Danger and its Design” en Minnesota Law Review (Vol. 94), pp. 1789-1866.

Loewenstein, Karl (1979): Teoría de la Constitución, segunda edición (Barcelona, Ariel).

McCormick, John P. (1999): Carl Schmitt's Critique of Liberalism (Cambridge, Cambridge University Press). 
O’Donnell, Daniel (1989): Protección internacional de los derechos humanos, segunda edición (Lima, CAJ).

Palacios Mc Bride, Rosa María (1988): La protección jurisdiccional de los derechos humanos durante el régimen de excepción (tesis de bachillerato en Derecho, Lima, PUCP).

Pérez Aguilera, Mar (2012): "Conflictividad social y vulneración de derechos" en Coordinadora Nacional de Derechos Humanos, Informe anual 20102011: Un año del gobierno de Ollanta Humala (Lima, CNDDHH), pp. 17-25. Pérez Royo, Javier (2005): Curso de Derecho constitucional, décima edición (Madrid, Marcial Pons).

Pérez Royo, Javier (2010): "La democracia frente al terrorismo global” en Pérez Royo, Javier (dir.), Terrorismo, democracia y seguridad, en perspectiva constitucional (Madrid, Marcial Pons), pp. 7-12.

Power Manchego-Muñoz, Jorge (1990): Constitución y estados de excepción (la Constitución peruana de 1979). (Lima, Asociación Acción y Pensamiento Democrático).

Questiaux, Nicole (Relatora Especial) (1982): Study of the Implications for Human Rights of Recent Developments Concerning Situations Known as States of Siege or Emergency (document E/CN. 4/Sub. 2/1982/15, 27 July 1982).

Rey de Castro Arena, Alejandro (2010): Republicanismo, nación y democracia. La modernidad politica en el Perú, 1821-1846 (Lima, UNMSM).

Rojas AMPuero, Daniel (1985): El régimen de excepción en la Constitución peruana de 1979 (tesis de bachillerato en Derecho, Lima, PUCP).

Rospigliosi, Fernando (2001): Montesinos y las Fuerzas Armadas (Lima, IEP).

Rossiter, Clinton (2011): Constitutional Dictatorship: Crisis Government in the Modern Democracies, seventh printing (New Jersey, Transaction Publishers).

Rubio Correa, Marcial (1989): "Fuerzas Armadas y Constitución en el Perú: 1979-1988” en A.A.V.V., La Constitución diez años después (Lima, Fundación Friedrich Naumann), pp. 223-260.

Rubio Correa, Marcial (1999): Estudio de la Constitución Política de 1993 (Lima, PUCP), tomo IV.

Rubio Correa, Marcial y Bernales Ballesteros, Enrique (1983): Constitución y sociedad política, segunda edición (Lima, Mesa Redonda Editores).

Sánchez Montenegro, Juan Pablo (2011): Las Fuerzas Armadas y el estado de emergencia como instrumento de su recuperación institucional durante el periodo 2001-2010 (tesis de licenciatura en Ciencia Política, Lima, PUCP). 
SCHEININ, Martin (Relator Especial sobre la promoción y protección de los derechos humanos y las libertades fundamentales en la lucha contra el terrorismo) (2010): Informe sobre su misión al Perú (documento A/HRC/16/51/Add. 3, ONU, Consejo de Derechos Humanos, 15 de diciembre de 2010).

Schмiтt, Carl (1985): La dictadura (Madrid, Alianza Editorial).

Schmitт, Carl (1998): Teología política (Buenos Aires, Struhart).

Siles Vallejos, Abraham (2014): "La dictadura en la República romana clásica como referente paradigmático del régimen de excepción constitucional” en Derecho PUCP (No 73), pp. 411-424.

Siles Vallejos, Abraham (2015): "La emergencia... en el corazón del constitucionalismo peruano: paradojas, aporías y normalización” en Themis - Revista de Derecho (No 67), pp. 73-84.

Siles Vallejos, Abraham (2015): "La lucha antiterrorista en el Perú: agujeros negros legales, agujeros grises y el arduo camino constitucional. Lecciones peruanas para la guerra contra el terrorismo global", en Derecho PUCP (No 75), pp. 75-94.

Siles Vallejos, Abraham (2017): "El pensamiento de Locke y Montesquieu como antecedente de la configuración constitucional de poderes de excepción ante emergencias políticas" (artículo inédito a ser publicado en Anuario de Investigación del CICAJ 2017, Lima, CICAJ-PUCP).

Soberón, Francisco y Jugo, Miguel (2010): “Cómo se violan hoy los derechos fundamentales? Derechos humanos y criminalización de la protesta”, en OXFAM, Informe Perú 2009-2010: Pobreza, desigualdad y desarrollo en Perú (Lima, OXFAM), pp. 58-67.

Tenorio SÁnchez, Pedro (2010): Constitución, derechos fundamentales y seguridad. Panorama comparativo (Pamplona, Civitas - Thomson Reuters).

Tusseau, Guillaume (2011): “The Concept of Constitutional Emergency Power: A Theoretical and Comparative Approach", en Archives for Philosophy of Law and Social Philosophy (Vol. 97, No 4), pp. 498-530.

Úbeda de Torres, Amaya (2007): Democracia y derechos humanos en Europa y en América. Estudio comparado de los sistemas europeo e interamericano de protección de los derechos humanos (Madrid, Editorial Reus).

United Nations Economic and Social Council UN Sub-Commission on Prevention of Discrimination and Protection of Minorities (1985): “The Siracusa Principles on the Limitation and Derogation Provisions in the Inter- 
national Covenant on Civil and Political Rights, U.N. Doc. E/CN.4/1985/4, Annex (1985)", en Human Rights Quarterly, (Vol. 7, No 1), pp. 3-14.

VARGas Jaramillo, Guillermo (1995): "Hábeas corpus en los estados de excepción:

Perú 1986-1987”, en Pensamiento constitucional (Año 2, No 2), pp. 203-227.

VergotTini, Giuseppe de (2004): "La difícil convivencia entre libertad y seguridad.

Respuesta de las democracias al terrorismo", en Revista de Derecho Político (No 61), pp. 11-36.

\section{NORMAS JURÍDICAS CITADAS}

Constitución de la República Bolivariana de Venezuela (1999, revisada en 2009). Constitución de los Estados Unidos (1787, revisada en 1992).

Constitución de Weimar (1919).

Constitución Española (1978, revisada en 2011).

Constitución Nacional Argentina (1853, revisada en 1994).

Constitución Política de Colombia (1991, revisada en 2013).

Constitución Política de la República del Perú (1933).

Constitución Política del Perú (1979).

Constitución Política del Perú (1993).

Convención Americana sobre Derechos Humanos "Pacto de San José, Costa Rica" (1969).

Decreto Legislativo No 738, que establece normas a las que deben sujetarse las Fuerzas Armadas al intervenir en las zonas no declaradas en Estado de Emergencia (El Peruano de 12 de noviembre de 1991).

Decreto Legislativo No 749, que modifica el art. 5 de la ley No 24.150 a fin de regular las relaciones del Comando Político Militar de las zonas declaradas en Emergencia con diversas autoridades de su jurisdicción (El Peruano de 12 de noviembre de 1991).

Decreto Legislativo No 1095, que establece reglas de empleo y uso de la fuerza por parte de las Fuerzas Armadas en el territorio nacional (El Peruano de 1 de septiembre de 2010).

Decreto Supremo No 019-2017-PCM, que prorroga el estado de emergencia en las provincias del Santa y Casma, en el departamento de Áncash (El Peruano de 5 de mayo de 2017).

Decreto Supremo No 031-2017-PCM, que prorroga el estado de emergencia en diversos distritos y provincias de los departamentos de Ayacucho, Huancavelica, Cusco y Junín (El Peruano de 12 de mayo de 2017). 
Decreto Supremo No 032-2017-PCM, que prorroga el estado de emergencia en el distrito de Echarate, provincia de La Convención, departamento de Cusco ( $E l$ Peruano de 12 de mayo de 2017).

Decreto Supremo No 036-2017-PCM, que prorroga el estado de emergencia en la Provincia Constitucional del Callao (El Peruano de 31 de mayo de 2017). Emergencies Act, R.S.C. de Canadá, 1985, c. 22 (4th Supp.).

Ley No 137 de 1994 de Colombia, por la cual se regulan los estados de excepción, de 3 de junio de 1994.

Ley No 24.150, que establece normas que deben cumplirse en los estados de excepción en que las Fuerzas Armadas asumen el control del orden interno, en todo o en parte del territorio (El Peruano de 7 de junio de 1985).

Ley No 25.397, Ley de Control Parlamentario sobre los actos normativos del Presidente de la República (El Peruano de 9 de febrero de 1992).

Ley No 25.410, que sustituye el artículo 2 del Decreto Legislativo No 738 ( $E l$ Peruano de 12 de marzo de 1992).

Ley No 28.222, que modifica la Ley No 25.410 (El Peruano de 18 de mayo de 2004). Ley No 28.237, Código Procesal Constitucional (El Peruano de 31 de mayo de 2004). Ley No 29.158, Ley Orgánica del Poder Ejecutivo (El Peruano de 20 de diciembre de 2007).

Ley No 29.166, que establece reglas de empleo de la fuerza por parte del personal de las Fuerzas Armadas en el Territorio Nacional (El Peruano de 20 de diciembre de 2007).

Ley Orgánica 4/1981 de España, de 1 de junio, de los estados de alarma, excepción y sitio.

Ley Orgánica sobre Estados de Excepción de Venezuela, de 15 de agosto de 2001. Pacto Internacional de Derechos Civiles y Políticos (1966).

Reglamento del Congreso de la República del Perú (El Peruano de 26 de junio de 1995).

\section{JURISPRUDENCIA CITADA}

Corte Interamericana de Derechos Humanos. Caso Zambrano Vélez y otros vs. Ecuador (2007). Fondo, reparaciones y costas. Sentencia de 4 de julio de 2007. Serie C No 166. 
Tribunal Constitucional del Perú. Caso de la ley No 24.150, sobre normas a cumplir en los estados de excepción en que las Fuerzas Armadas asumen el control del orden interno (2004). Sentencia de 16 de marzo de 2004 (www. tc.gob.pe, 23 de agosto de 2004). Expediente 017-2003-AI-TC.

Tribunal Constitucional del Perú. Caso de la ley No 24.150, sobre normas a cumplir en los estados de excepción en que las Fuerzas Armadas asumen el control del orden interno (2004). Resolución aclaratoria de 31 de agosto de 2004 (www.tc.gob.pe, 28 de septiembre de 2004). Expediente 017-2003-AI-TC.

Tribunal Constitucional del Perú. Caso Lizana Puelles (2005). Sentencia de 8 de noviembre de 2005 (www.tc.gob.pe, 8 de noviembre de 2005). Expediente 017-2003-AI-TC.

Tribunal Constitucional del Perú. Caso Castillo Chirinos (2006). Sentencia de 21 de julio de 2006 (www.tc.gob.pe, 27 de julio de 2006). Expediente 27302006-PA/TC.

Tribunal Constitucional del Perú. Caso de la Ley No 29.166, sobre las reglas del empleo de la fuerza por las Fuerzas Armadas en el territorio nacional (2009). Sentencia de 9 de septiembre de 2009 (www.tc.gob.pe, 14 de septiembre de 2009). Expediente 00002-2008-AI.

Tribunal Constitucional del Perú. Caso de la Ley No 29.166, sobre las reglas del empleo de la fuerza por las Fuerzas Armadas en el territorio nacional (2009). Resolución aclaratoria de 17 de septiembre de 2009 (www.tc.gob.pe, 18 de septiembre de 2009). Expediente 00002-2008-AI.

Tribunal Constitucional del Perú. Caso del Decreto Legislativo No 1095, sobre las reglas de uso de la fuerza por las Fuerzas Armadas en el territorio nacional (2015). Sentencia de 8 de julio de 2015 (www.tc.gob.pe, 18 de agosto de 2015). Expediente 00022-2011-PI/TC.

Tribunal Europeo de Derechos Humanos. Case of Lawless vs. Ireland (1961). Sentencia de 1 de julio de 1961.

Tribunal Europeo de Derechos Humanos. Case of A. and Others vs. United Kingdom (2009). Sentencia de 19 de febrero de 2009. 